\title{
Divergent behavior in markets with idiosyncratic private information *
}

\author{
David Goldbaum ${ }^{\dagger}$
}

\begin{abstract}
A state of perpetually evolving divergent trading strategies is the natural consequence of a market with idiosyncratic private information. In the face of intrinsic uncertainty about other traders' strategies, participants resort to learning and adaptation to identify and exploit profitable trading opportunities. Model-consistent use of market-based information generally improves price performance but can inadvertently produce episodes of sudden mis-pricing. The paper examines the impact of trader's use of information and bounded rationality on price efficiency.
\end{abstract}

Keywords: Heterogeneous Agents, Efficient Markets, Learning, Dynamics, Computational Economics

(JEL Codes: G14, C62, D82)

*I thank Carl Chiarella and members of SydneyAgents for feedback throughout the development of this paper and for the suggestions of an anonymous referee. I gratefully acknowledge the financial support of the Paul Woolley Centre for Capital Market Dysfunctionality.

${ }^{\dagger}$ Economics Discipline Group, University of Technology Sydney, PO Box 123 Broadway, NSW 2007 Australia, david.goldbaum@uts.edu.au 


\section{Introduction}

Financial markets exhibit extraordinary diversity in investor trading strategies. Widespread among traders are attempts to extract rent through market participation. Vigorous trading and extensive market commentary suggests a lack of uniformity among market participants and possible disagreement as to the true price determination process.

This paper explores a process by which reasonable data-driven adaptation and learning by market participants shape market evolution. The developed model places traders into an imperfect information environment in which the rational expectations equilibrium is analytically inaccessible to the traders for its dependence on a hidden endogenous state variable. An optimizing approach has traders update trading strategies through learning and adaptation. The process can continue without end due to the model's absence of a fixed point. In the developed setting market-based strategies have a role, potentially improving market efficiency, trading profitably by in extracting information from market observables. To the market's potential detriment, the traders lack all of the information necessary to employ the market information without error and without potentially distorting the market price.

The financial market setting draws on models of divergent beliefs, learning, and adaptive behavior. Foundational investigations such as Hellwig (1980) and Grossman and Stiglitz (1980) considered the role of markets in aggregating and filtering information and the equilibrium implications of the market participants trading on others' private information extracted from the market. Investigations such as Frankel and Froot (1990), Day and Huang (1990), De Long, Shleifer, Summers and Waldmann (1990a), and De Long, Shleifer, Summers and Waldmann (1990b), consider the possible sustainability of multiple beliefs in static settings. Subsequent analysis considers heterogeneous traders in dynamic settings that endogenize current market impact. One approach has traders choose between discrete information options based on past performance. For the models developed in Brock and LeBaron (1996), Brock and Hommes (1998), De Grauwe and Grimaldi (2005), and Giardina and Bouchaud (2003), among others, the popularity of a particular information source depend directly on relative performance. Alternatively, relative performance determines the innovation in popularity in Sethi and Franke (1995), Branch and McGough (2008), and Goldbaum (2005). ${ }^{1}$ Another source of market evo-

\footnotetext{
${ }^{1}$ Wealth accumulation to those using the particular information or strategy is another mechanism generating evolution in market impact, as in Chiarella and He (2001), Farmer and Joshi (2002), Chiarella, Dieci and Gardini
} 
lution comes from traders updating how they use information in developing a trading strategy using statistical learning tools, such as Marcet and Sargent (1989a), Marcet and Sargent (1989b), and Evans and Honkapohja (2001). Non-statistical approaches such as the genetic algorithms in LeBaron, Arthur and Palmer (1999) and Bullard and Duffy (1999) offer mechanisms by which traders can improve available trading tools, generating evolution in market behavior as strategies improve, following the lessons suggested by recent past events.

Failure by a fundamental trader dominated market to achieve perfect efficiency creates an opportunity for market-based traders to extract information from the price. To make the non-fundamental information viable, models such as developed in Grossman and Stiglitz (1980), Evans and Ramey (1992), Brock and Hommes (1998), and Chiarella and He (2003) offer marketbased trading as a low-cost alternative to acquiring the same information known to an informed group of traders. The alternative approach to information adopted in this paper handicaps fundamental information with private idiosyncratic noise, as in Brock and LeBaron (1996), while making contemporaneous the market extraction of the information, as in Grossman and Stiglitz (1980). In this environment, market-based trading offers the potential to take advantage of the market's filtering properties to gain profitable information not possessed by any individual fundamentally informed trader. The resulting competitive or even superior market-based information, achieved without imposition of cost on the private fundamental information, is, to my knowledge, unique to the developed model.

Market-based trading strategies, particularly low cost trend-following rules, introduce instability in the dynamic financial market system in Brock and LeBaron (1996), Brock and Hommes (1998), De Grauwe and Grimaldi (2005), Giardina and Bouchaud (2003), Goldbaum (2003), Lux (1998), and Panchenko, Gerasymchuk and Pavlov (2013). In contrast, I present a model in which market-based information is capable of generating profits while improving market efficiency. The model captures an environment inherently supportive of traders' use of market-based information. Model mis-pricing is thus not hardwired into the market-based trading strategy. Mis-pricing arises only circumstantially when traders, for historical or path dependent reasons, use market-based information inappropriately for the particular realized

(2006), and Sciubba (2005). Other mechanisms have been considered as well. Lux (1995), for example, relies on investor sentiment. Routledge (1999) incorporates dispersion through random encounters. Franke and Westerhoff (2012) includes reversion to fundamental based on the price error. Dispersion occurs over a network in Panchenko, Gerasymchuk and Pavlov (2013). 
state. These features are impossible without informative price innovations. Without useful information arising out of the market, market-based strategies' only service to the traders is to ride self-generated popular sentiment. The strategy serve no purpose other than to distort the market. Similarly, market-based trading loses its effectiveness if the information accessed is out of date. ${ }^{2}$

What the modeled traders do not know for certain is how to interpret the market information. Addressing this uncertainty is confounded by the self-referential aspect of beliefs and by the model's state-dependent mapping between market observables and investment fundamentals. The former can be overcome with a convergent learning process but only in the absence of continued evolution in the latter. ${ }^{3}$ Following Goldbaum and Panchenko (2010), the analysis points to the role of the population process in shaping market behavior. The presence of the fixed point anchors the asymptotic behavior of the market. The interaction between the selfreferential learning and the adaptive behavior can be either a source of asymptotic stability or instability in the absence of a fixed point.

Boundedly rational behavior is a common feature of models exploring trader heterogeneity, divergent beliefs, and learning. Analysis of the model includes an exploration of bounded rationality imposed through memory length. Brock and LeBaron (1996) and LeBaron, Arthur and Palmer (1999) highlight the stabilizing influence of long memory on the dynamic system. Long memory, for example, helps to stabilize the inherently destabilizing cobweb model in Branch and McGough (2008) to produce asymptotically similar behavior between the replicator dynamic $(\mathrm{RD})$ and the discrete choice dynamic (DCD) processes.

Incorporating individual rationality of an agent unaware of the correct model, the misspecified equilibrium of Branch and Evans (2006) and the mixed expectations equilibrium of Guse (2010) both describe a fixed point supporting heterogeneous beliefs. The bounded rationality appears in the form of an under-parameterized model that nonetheless appears consistent with the actual law of motion. ${ }^{4}$ Goldbaum (2006) imposes constraints consistent with a rational

\footnotetext{
${ }^{2}$ In Brock and Hommes (1998) the fundamental value is constant but the market-based traders nonetheless extrapolate from past returns. All price innovations generated by the model are spurious, a rather extreme notion of financial market disfunctionality but one well reflected in the data presented in Shiller (2015) according to Schmitt and Westerhoff (2017b).

${ }^{3}$ Bullard (1994), Bullard and Duffy (2001), and Chiarella and He (2003) offer examples with non-convergence in learning.

${ }^{4}$ The mis-specification of the under-parameterized minimum squared variance model is absorbed into the error term. In Guse (2010), the mis-specified model persists supported by a cost advantage.
} 
expectations equilibrium solution on the traders' behavior, though the solution itself is hidden. Relaxing these rationality restrictions and incorporating other boundedly rational behavior introduces a variety of mechanisms through which mispricing arises.

The analysis of this paper offers new insight into the market consequences of imperfect idiosyncratic information by analytically extending the model in Goldbaum (2006) and developing a number of new application treatments. The model is attractive for supporting divergent beliefs without arbitrary costs or limitations on choice. Explored are the role of dynamic processes, bounded rationality, and memory in shaping near-term evolution and asymptotic behavior.

The paper proceeds as follows. Section 2 introduces the structure of the financial market, trader behavior, and the available information. Also developed in the section is a rational expectations equilibrium as it depends on a hidden endogenous state variable. This provides a reference against which to compare market price and beliefs under boundedly rational settings. Both the replicator and discrete choice dynamic models for driving the state variable are evaluated. A model of trader learning is also developed. Different notions of bounded rationality as they may apply to traders in the financial market are discussed in this section as well. Section 3 offers computational analysis of the market, highlighting the interactions between the state variable, learning, and rationality. Final thoughts are included in Section 4.

\section{Model and development}

\subsection{The basic model and market clearing}

A large population of $N$ traders trade a risky dividend-paying asset and a risk-free bond paying $R$. The risky asset can be purchased at price $p_{t}$ in period $t$ and is subsequently sold at price $p_{t+1}$ after paying the holder dividend $d_{t+1}$ in period $t+1$. The dividend process follows an exogenous $\mathrm{AR}(1)$ process

$$
d_{t+1}=\phi d_{t}+\epsilon_{t+1}, \phi \in(0,1)
$$

normalized to mean zero with innovations distributed $\epsilon_{t} \sim \operatorname{IIDN}\left(0, \sigma_{\epsilon}^{2}\right)$. Available to the traders for time $t$ trading is a combination of public and private fundamental information as well as 
market-based information,

$$
Z_{i t}=\left\{s_{i t}, p_{t}, d_{t}, p_{t-1}, d_{t-1}, \ldots\right\}
$$

The dividend $d_{t}$ is paid at the start of the period and its value is public knowledge at the time of trade. The Walrasian price $p_{t}$ is not yet realized but can be conditioned on when the trader submits a demand function. Each trader has access to a private idiosyncratically noisy signal, $s_{i t}$, centered on next period's innovation,

$$
\begin{aligned}
& s_{i t}=\epsilon_{t+1}+e_{i t} \\
& e_{i t} \sim \operatorname{IIDN}\left(0, \sigma_{e}^{2}\right) .
\end{aligned}
$$

In forming demand for the risky asset, traders use available information to forecast the future payoff, $p_{t+1}+d_{t+1}$. The population is heterogeneous in how much weight to place on fundamental versus market-based information. The proper balance turns out to be state dependent and hidden so that the selective use of information will be consistent with the developed model. At one extreme of trader types, the "fundamental" trader completely discounts market variables as a source of useful information, relying entirely on public and private fundamental information to form expectations. At the other extreme, the "market-based" trader uses public information to the exclusion of the noisy private signal. In each period, the traders select between the two extreme positions, ${ }^{5}$

$$
\begin{aligned}
Z_{i t} & \in\left\{Z_{i t}^{F}, Z_{i t}^{M}\right\} \\
Z_{i t}^{F} & =\left\{s_{i t}, d_{t}, d_{t-1}, \ldots\right\} \\
Z_{i t}^{M}=Z_{t}^{M} & =\left\{p_{t}, d_{t}, p_{t-1} d_{t-1}, \ldots\right\} .
\end{aligned}
$$

The equity demand component of the agents' optimal control problem collapses to a spot market decision when using negative exponential utility. Given prices $\left\{p_{t}\right\}_{t=0}^{\infty}$, optimal equity

\footnotetext{
${ }^{5}$ Alternatively, allow every trader use of $Z_{i t}=Z_{i t}^{F} \cup Z_{i t}^{M}$. There is no REE solution as the trader should optimally ignore the private signal and rely on the REE perfectly revealing $p_{t}$ to extract $\epsilon_{t+1}$, a strategy that is inconsistent with an informative price if universally employed. See Goldbaum (2006) for the derivation and for simulations of learning based on this alternate information model.
} 
demand is given by

$$
\hat{q}_{i t}^{k}\left(p_{t}\right)=\left(E\left(p_{t+1}+d_{t+1} \mid Z_{i t}^{k}\right)-R p_{t}\right) / \gamma \sigma_{k t}^{2}, k=F, M \text { and for all } t
$$

with $\sigma_{k t}^{2}=\operatorname{Var}_{i t}\left(p_{t+1}+d_{t+1} \mid Z_{i t}^{k}\right)$. The competitive equilibrium consists of a population of $N=N_{t}^{F}+N_{t}^{M}$ optimizing traders and a price series $\left\{p_{t}\right\}_{t=0}^{\infty}$ that clears the spot market in equities in each period.

A rational expectations equilibrium-consistent fundamental trader belief has $p_{t}$ that is linear in the orthogonal components, known concurrent dividend, $d_{t}$, and future innovation, $\epsilon_{t+1}$, of the form, ${ }^{6}$

$$
p_{t}=\frac{1}{R-\phi}\left(\phi d_{t}+\alpha \epsilon_{t+1}\right)
$$

Subsequent analysis will reveal that this perceived price structure is consistent with the actual price structure under select bounded rationality conditions as well. Iterated expectations applied to (1) and (4) produce the fundamental information based forecast of the expected payoff to the risky asset,

$$
E\left(p_{t+1}+d_{t+1} \mid Z_{i t}^{F}\right)=\left(\frac{R}{R-\phi}\right) E\left(d_{t+1} \mid Z_{i t}^{F}\right)
$$

Independence of the expected payoff from the fundamental traders' $\alpha$ is convenient for internal consistency as the market clearing price is robust to trader's belief, right or wrong, rational or irrational, regarding the value $\alpha$. A deficiency in the fundamental trader understanding of the pricing of $\epsilon_{t+1}$ does not impact the market. As will become apparent, this implies that the fundamental traders do not necessarily need to anticipate the market-based traders in order to hold consistent beliefs.

Fundamental traders project $d_{t+1}$ on their available $Z_{i t}^{F}$ information, obtaining the mean squared error minimizing forecast with

$$
E\left(d_{t+1} \mid Z_{i t}^{F}\right)=\phi d_{t}+\beta s_{i t}
$$

and $\beta=\sigma_{\epsilon}^{2} /\left(\sigma_{\epsilon}^{2}+\sigma_{e}^{2}\right)$. Thus, fundamental traders' uncertainty, the consequence of awareness

\footnotetext{
${ }^{6}$ This is equivalent to the Goldbaum (2006) price, $p_{t}=b_{0}+b_{1} d_{t}+b_{2} d_{t+1}$, with $B_{1}=(R-\phi)\left(b_{1}+\phi b_{2}\right) / \phi$ and $B_{2}=(R-\phi) b_{2}$. The orthogonal components, $d_{t}$ and $\epsilon_{t+1}$, allow clear distinction of what the market correctly prices and where it fails.
} 
of the idiosyncratic component of their signal, leads to fundamental trader down-weighting of the signal.

The market-based traders employ a forecasting model that is linear in all relevant observables consistent to forecasting the following period's payoff,

$$
E\left(p_{t+1}+d_{t+1} \mid Z_{t}^{M}\right)=c_{0 t}+c_{1 t} p_{t}+c_{2 t} d_{t}
$$

Let $q_{t}^{k}$ be the average demand of the population of type $k$ traders, $k=F, M$. Based on individual expectations (5) and $(7),{ }^{7}$

$$
\begin{aligned}
q_{t}^{F} & =\left(\frac{R}{R-\phi}\left(\phi d_{t}+\beta \epsilon_{t+1}\right)-R p_{t}\right) / \gamma \sigma_{F t}^{2} \\
q_{t}^{M} & =\left(c_{0 t}+c_{2 t} d_{t}-\left(R-c_{1 t}\right) p_{t}\right) / \gamma \sigma_{M t}^{2} .
\end{aligned}
$$

Though no individual fundamental trader knows the value of $\epsilon_{t+1}$, it is reflected in $q_{t}^{F}$ without noise as aggregation filters the idiosyncratic component of $s_{i t}$. With portion $n_{t}$ of traders using the fundamental approach and $1-n_{t}$ employing the market-based approach, a consistent Walrasian price function is

$$
p_{t}=B_{0 t}+\frac{1}{R-\phi}\left(B_{1}\left(n_{t}, \mathbf{c}_{t}\right) \phi d_{t}+B_{2}\left(n_{t}, \mathbf{c}_{t}\right) \epsilon_{t+1}\right),
$$

in which $\mathbf{c}_{t}$ represents a vector of the coefficients in (7).

The coefficients of (10) solve the market clearing condition, $n_{t} q_{t}^{F}+\left(1-n_{t}\right) q_{t}^{M}=0$, at

$$
\begin{aligned}
B_{0}\left(n_{t}, \mathbf{c}_{t}\right) & =\frac{c_{0 t}\left(1-n_{t}\right) \kappa_{t}}{n_{t} R+\left(1-n_{t}\right)\left(R-c_{1 t}\right) \kappa_{t}}, \\
B_{1}\left(n_{t}, \mathbf{c}_{t}\right) & =\frac{n_{t} R+\frac{1}{\phi}(R-\phi)\left(1-n_{t}\right) c_{2 t} \kappa_{t}}{n_{t} R+\left(1-n_{t}\right)\left(R-c_{1 t}\right) \kappa_{t}} \\
B_{2}\left(n_{t}, \mathbf{c}_{t}\right) & =\frac{n_{t} R \beta}{n_{t} R+\left(1-n_{t}\right)\left(R-c_{1 t}\right) \kappa_{t}},
\end{aligned}
$$

where $\kappa_{t}=\sigma_{F t}^{2} / \sigma_{M t}^{2}$. Conditional variance, $\sigma_{k t}^{2}=\operatorname{Var}_{i t}\left(p_{t+1}+d_{t+1} \mid Z_{i t}^{k}\right)$, is derived using (10)

\footnotetext{
${ }^{7}$ Formally, $q_{t}^{F}=R\left(\left((1-\beta) \phi d_{t}+\beta\left(\epsilon_{t+1}+\frac{1}{n_{t} N} \sum e_{i t}\right)\right) /(R-\phi)-p_{t}\right) / \gamma \sigma_{F t}^{2}$ but with a large $n_{t} N$ population of fundamental traders, the average idiosyncratic error is approximately zero.
} 
and the appropriate (5) or (7) with, ${ }^{8}$

$$
\begin{aligned}
p_{t+1}+d_{t+1}-E\left(p_{t+1}+d_{t+1} \mid Z_{i t}^{F}\right)= & \frac{1}{R-\phi}\left(\left(B_{1 t}-1\right) \phi^{2} d_{t}+\left(R(1-\beta)+\phi\left(B_{1 t}-1\right)\right) \epsilon_{t+1}\right. \\
& \left.+B_{2 t+1} \epsilon_{t+2}-\beta R e_{i t}\right) \\
p_{t+1}+d_{t+1}-E\left(p_{t+1}+d_{t+1} \mid Z_{t}^{M}\right)= & \frac{1}{R-\phi}\left(\phi\left(R+\phi\left(B_{1 t}-1\right)\right)-\phi B_{1 t} c_{1 t}-(R-\phi) c_{2 t}\right) d_{t} \\
& \left.+\left(R+\phi\left(B_{1 t}-1\right)-c_{1 t} B_{2 t}\right) \epsilon_{t+1}+B_{2 t+1} \epsilon_{t+2}\right) .
\end{aligned}
$$

In the order in which they appear in (14), fundamental trader error arises (i) when the market mis-prices dividends $\left(B_{1 t} \neq 1\right.$ ), (ii) as a result of down-weighting private information due to the noise in the signal $(\beta \neq 1)$, (iii) from the unobservable component of $p_{t+1}\left(\epsilon_{t+2} \neq 0\right)$, and (iv) the trader's private signal error $\left(e_{i t} \neq 0\right)$. Market based trader error arises as a consequence of (i) inconsistency between $c_{1 t}$ and $c_{2 t}\left((R-\phi) c_{2 t} \neq \phi\left(R-c_{1 t}\right)\right.$ and market mispricing dividends $\left(B_{1 t} \neq 1\right)$, (ii) misinterpretation of the market information $\left(B_{2 t} c_{1 t} \neq R\right.$ ), and (iii) from the unobservable component of $p_{t+1}\left(\epsilon_{t+2} \neq 0\right)$. The developed analytical solution will identify conditions under which certain sources of error can be eliminated.

\subsection{A Rational Expectations Equilibrium}

The Grossman and Stiglitz (1980) rational expectations equilibrium (REE) has two components. The traders must form rational beliefs based on the information available to them. This is the basis for the rational expectations equilibrium defined below. Additionally, the Grossman and Stiglitz traders must make an ex post correct decision regarding whether or not to receive the costly private signal. This latter component of rationality is consistent with a Nash equilibrium.

Definition 1. An $n_{t}$-dependent rational expectations equilibrium describes a market in which the coefficients of the market-based strategy in (7) correctly reflect the projection of $p_{t+1}+d_{t+1}$ on $d_{t}$ and $p_{t}$. Further, the fundamental strategy employs beliefs about the price function consistent with (4) and forecast dividends according to (6).

Recall $\kappa=\sigma_{F}^{2} / \sigma_{M}^{2}$. The $n_{t}$-dependent Rational Expectations Equilibrium $\left(\operatorname{REE}\left(n_{t}\right)\right)$ solu-

\footnotetext{
${ }^{8}$ Error in $B_{0 t}$ is possible but not considered. In the de-meaned dividend and price series, $B_{0 t}=0$ is the rationally consistent belief.
} 
tion is the $B_{2}$ and $\kappa$ that solve (18) and (21) of the following so that, for $n_{t} \in(0,1]$,

$$
\begin{aligned}
p_{t}^{*}=p_{t}^{*}\left(n_{t}\right) & =\frac{1}{R-\phi}\left(\phi B_{1}^{*} d_{t}+B_{2}^{*}\left(n_{t}\right) \epsilon_{t+1}\right) \\
B_{1}^{*} & =1 \\
B_{2}^{*}\left(n_{t}\right) & =\frac{n_{t} \beta+\left(1-n_{t}\right) \kappa^{*}\left(n_{t}\right)}{n_{t}+\left(1-n_{t}\right) \kappa^{*}\left(n_{t}\right)} \\
c_{1}^{*}\left(n_{t}\right) & =\frac{R}{B_{2}^{*}\left(n_{t}\right)}=\frac{R\left(n_{t}+\left(1-n_{t}\right) \kappa^{*}\left(n_{t}\right)\right)}{n_{t} \beta+\left(1-n_{t}\right) \kappa^{*}\left(n_{t}\right)} \\
c_{2}^{*}\left(n_{t}\right) & =\frac{\phi}{R-\phi}\left(R-c_{1}^{*}\left(n_{t}\right)\right)=-\frac{n_{t} R(1-\beta) \phi}{(R-\phi)\left(n_{t} \beta+\left(1-n_{t}\right) \kappa^{*}\left(n_{t}\right)\right)} \\
\kappa^{*}\left(n_{t}\right) & =\frac{\sigma_{F}^{*}\left(n_{t}\right)^{2}}{\sigma_{M}^{*}\left(n_{t}\right)^{2}}=1+\frac{(1-\beta) R^{2}}{B_{2}^{*}\left(n_{t}\right)^{2}}
\end{aligned}
$$

where $\kappa^{*}$ follows from

$$
\begin{aligned}
\sigma_{F}^{*}\left(n_{t}\right)^{2} & =\left((1-\beta)\left(\frac{R}{R-\phi}\right)^{2}+\frac{B_{2}^{*}\left(n_{t}\right)^{2}}{(R-\phi)^{2}}\right) \sigma_{\epsilon}^{2} \\
\sigma_{M}^{*}\left(n_{t}\right)^{2} & =\frac{B_{2}^{*}\left(n_{t}\right)^{2}}{(R-\phi)^{2}} \sigma_{\epsilon}^{2} .
\end{aligned}
$$

The $\operatorname{REE}\left(n_{t}\right)$ price $p_{t}^{*}$ is consistent with the fundamental trader beliefs. With $B_{1}^{*}=1$, the known dividend is properly priced by the market and by the fundamental traders. As previously identified, $\alpha=B_{2}^{*}$ is not required for consistency as the fundamental trader's investment decision is independent of $\alpha$. Accuracy for the fundamental trader comes from accurately predicting $\epsilon_{t+1}$ and is unaffected by the possible mismatch between $\alpha$ and $B_{2 t}$.

The closed form solution reveals $B_{2}^{*}\left(n_{t}\right)$ to be monotonically decreasing in $n_{t}$ with $B_{2}^{*}\left(n_{t}\right) \in$ $[\beta, 1) .{ }^{9}$ At $n_{t}=1, B_{2}^{*}(1)=\beta$. As $n_{t} \rightarrow 0, B_{2}^{*}\left(n_{t}\right) \rightarrow 1$, For $n_{t}=0$, then $B_{2}^{*}(0)=0$ as derived from the consistent solution $c_{1}^{*}(0)=0$ and $c_{2}^{*}(0)=R$ while, $c_{1}^{*}\left(n_{t}\right) \rightarrow R$, and $c_{2}^{*}\left(n_{t}\right) \rightarrow 0$ as $n_{t} \rightarrow 0$. The rational market-based traders are also aware that $c_{0}^{*}=0$ as consistent with the unbiased $B_{0 t}=0$. Thus, as $n_{t}$ declines, the $\operatorname{REE}\left(n_{t}\right)$ price becomes increasingly accurate at reflecting $\epsilon_{t+1}$.

\footnotetext{
${ }^{9}$ Using (21) in (18) results in a trinomial expression in $B_{2}^{*}\left(n_{t}\right)$ which can be solved for a closed form solution. The solution is long and unenlightening and thus excluded from the paper. Of the three roots, only one is real. It is the real root that is depicted in Figure 1.
} 
Identify $p_{t}^{0}, p_{t}^{1}$, and $p_{t}^{F}$ according to

$$
\begin{aligned}
p_{t}^{0} & \left.\equiv p_{t}^{*}(1)\right|_{\beta=0}=\frac{\phi}{R-\phi} d_{t}, \\
p_{t}^{1} & \left.\equiv p_{t}^{*}\left(n_{t}\right)\right|_{\beta=1}=\frac{1}{R-\phi}\left(\phi d_{t}+\epsilon_{t+1}\right)=\frac{1}{R-\phi} d_{t+1}, \\
p_{t}^{F} & \equiv p_{t}^{*}(1)=\frac{1}{R-\phi}\left(\phi d_{t}+\beta \epsilon_{t+1}\right) .
\end{aligned}
$$

Here, $p_{t}^{0}$ and $p_{t}^{1}$ represent the price at the two information extremes as determined by the accuracy of the private signal. Zero content in the signal, with $\sigma_{\epsilon} \rightarrow \infty$, results in $\beta=0$. Zero error, with $\sigma_{\epsilon}=0$, results in $\beta=1$. Prices $p_{t}^{0}$ and $p_{t}^{1}$ also correspond to the Fama (1970) semi-strong and strong form efficient prices, respectively. The $p_{t}^{F}$ represents the price at the extreme of a market populated by only fundamental traders. The $\operatorname{REE}\left(n_{t}\right)$ solution produces $B_{2}^{*}\left(n_{t}\right) \in[\beta, 1], p_{t}^{*}\left(n_{t}\right) \in\left[p_{t}^{F}, p_{t}^{1}\right]$ with $\lim _{n_{t} \rightarrow 0} p_{t}^{*}\left(n_{t}\right)=p_{t}^{1}$. That is, the presence of the marketbased traders moves the market towards the efficient market price. Since $p_{t}^{*}(0)=p_{t}^{0}$ there is a Grossman and Stiglitz (1980) type discontinuity at $n_{t}=0$.

Define performance in terms of individual profit,

$$
\pi_{i t}^{k}=q_{i t}^{k}\left(p_{t+1}+d_{t+1}-R p_{t}\right)
$$

The $\operatorname{REE}\left(n_{t}\right)$ generates expected profits, for $n_{t} \in(0,1]$,

$$
\begin{aligned}
& E\left(\pi_{F t}^{*}\right)=\left(1-n_{t}\right) \Delta_{t}^{*} \\
& E\left(\pi_{M t}^{*}\right)=-n_{t} \Delta_{t}^{*}
\end{aligned}
$$

so that $E\left(\pi_{F}^{*}-\pi_{M}^{*}\right)=\Delta_{t}^{*}$, where

$$
\Delta^{*}\left(n_{t}\right)=-\left(\frac{1-\beta}{n_{t}+\left(1-n_{t}\right) \kappa^{*}\left(n_{t}\right)}\right)^{2}\left(\frac{R}{R-\phi}\right)^{2} \frac{n_{t} \sigma_{\epsilon}^{2}}{\sigma_{M}^{* 2}}
$$

That $\Delta^{*}\left(n_{t}\right)<0$ for all $n_{t} \neq 0$ reveals the benefit to extracting filtered information from the $\operatorname{REE}\left(n_{t}\right)$ market over direct access to noisy information.

The $\operatorname{REE}\left(n_{t}\right)$ solution has two deficiencies.

1. $\operatorname{REE}\left(n_{t}\right)$ solution cannot be a Nash equilibrium: The opening for profitable employment 
of the market-based information follows from $p_{t}^{F} \in\left[p_{t}^{0}, p_{t}^{1}\right]$, introducing predictability in the price as a consequence of $\epsilon_{t+1}$ only partially reflected in $p_{t}$ while fully reflected in $p_{t+1}$. For $n_{t}>0$, the market-based traders outperform the fundamental traders so that ex-post, if the $\operatorname{REE}\left(n_{t}\right)$ market is achieved, the fundamental traders would prefer to have chosen to employ market-based information. As in Grossman and Stiglitz (1980), at $n_{t}=0$ there is no information content in the price so that the market-based strategy fails.

2. While consistency between the market and fundamental trader beliefs does not rely on the traders knowing $n_{t}$, the same is not true for the market-based traders. Without knowledge of $n_{t}$, there is no basis for correctly identifying $c_{1}^{*}\left(n_{t}\right)$ and $c_{2}^{*}\left(n_{t}\right)$.

The remainder of the paper examines whether the market-based traders can achieve the $\operatorname{REE}\left(n_{t}\right)$ beliefs without directly observing $n_{t}$ and the consequence of their efforts on the market. In general, the market cannot address both deficiencies simultaneously. If the fundamental traders accept inferior performance so that $n_{t}$ stabilizes, then the market-based traders can achieve $\operatorname{REE}\left(n_{t}\right)$ without directly observing $n_{t}$. Alternatively, when the market-based traders are unable to identify the correct $c_{1}^{*}\left(n_{t}\right)$ and $c_{2}^{*}\left(n_{t}\right)$ there is room in the market for profitable use of the fundamental information.

\subsection{Trader Accommodations}

Without knowledge of $n_{t}$, the market-based traders employ possibly incorrect beliefs, $c_{1 t} \neq$ $c_{1}^{*}\left(n_{t}\right)$ and $c_{2 t} \neq c_{2}^{*}\left(n_{t}\right)$. With $c_{1 t}$, the market-based trader extracts $\epsilon_{t+1}$ from $p_{t}$. The $c_{2 t}$ assists in the information extraction by controlling for the known impact $d_{t}$ has on $p_{t}$. In addition, all traders need to know the variance associated with their forecast error to properly set demand. Both conditional variance terms are $n_{t}$ dependent. Considered here is the impact of trader error on the market clearing price under different belief regimes.

All of the considered markets will impose the rational market-based traders belief $c_{0 t}=0$ as this solution is readily available to traders and independent of other market conditions.

\subsubsection{Bounded rationality with model-consistent beliefs}

Regardless of the accuracy of $c_{1 t}$, information extraction from $p_{t}$ is improved if the trader uses the $c_{1 t}$-consistent $c_{2 t}=c_{2}^{*}\left(c_{1 t}\right)$ according to the relationship expressed in (20). A high 


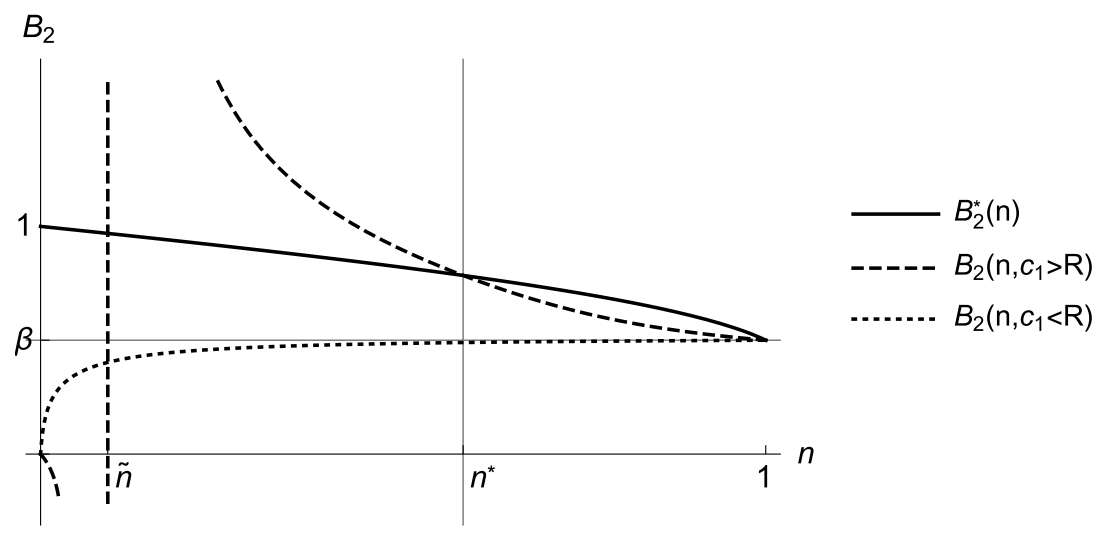

Figure 1: $B_{2}^{*}\left(n_{t}\right)$ and $B_{2}\left(n_{t}, c_{1 t}\right)$ for both $c_{1 t}>R$ and $c_{1 t}<R . n^{*}\left(c_{1 t}\right)$ is the inverse of $c_{1 t}=c_{1}^{*}\left(n_{t}\right)$ indicating the value of $n_{t}$ consistent with the market-based trader beliefs. $\tilde{n}\left(c_{1 t}\right)$ is the lower bound on the $n_{t}$ producing valid prices.

sophistication boundedly rational (HSBR) population employing $c_{2 t}=c_{2}^{*}\left(c_{1 t}\right)$ eliminates the $d_{t}$ term in the market-based trader's error in (15). The remaining market-based traders error arises from ignorance of $n_{t}$ that leads to error in identifying $\epsilon_{t+1}$ only.

Employing $c_{2 t}=c_{2}^{*}\left(c_{1 t}\right)$ results in $B_{1}\left(n_{t}, c_{1 t}\right)=1$ in $(13)$ so that the market as a whole correctly prices $d_{t}$. The market clearing price,

$$
p\left(n_{t}, c_{1 t}\right)=\frac{1}{R-\phi}\left(\phi d_{t}+B_{2}\left(n_{t}, c_{1 t}\right) \epsilon_{t+1}\right),
$$

remains consistent with fundamental beliefs regardless of the value of $c_{1 t}$ and resulting $B_{2}\left(n_{t}, c_{1 t}\right)$,

$$
B_{2 t}=B_{2}\left(n_{t}, c_{1 t}\right)=\frac{n_{t} R \beta}{n_{t} R+\left(1-n_{t}\right)\left(R-c_{1 t}\right) \kappa\left(n_{t}, c_{1 t}\right)}
$$

As capture in Figure 1, an important distinction between $B_{2}^{*}\left(n_{t}\right)$ and $B_{2}\left(n_{t}, c_{1 t}\right)$ is that while $B_{2}^{*}\left(n_{t}\right) \in[\beta, 1], B_{2}\left(n_{t}, c_{1 t}\right)$ is unbounded. Correct beliefs by the market-based traders produces a well behaved $p_{t}^{*}\left(n_{t}\right) \in\left[p_{t}^{F}, p_{t}^{1}\right]$, so that the presence of market-based traders improves market efficiency. The error introduced by $c_{1 t} \neq c_{1}^{*}\left(n_{t}\right)$ is potentially unbounded. With $\kappa>0$, for $c_{1 t}>R$ there exists some $\tilde{n}_{t}=\tilde{n}\left(c_{1 t}\right) \in(0,1)$ at which the denominator of (29) is zero. From $n_{t}=1, B_{2}\left(1, c_{1 t}\right)=\beta$ and monotonically increases towards $+\infty$ as $n_{t} \rightarrow \tilde{n}\left(c_{1 t}\right)$. For $n_{t}<\tilde{n}\left(c_{1 t}\right), B_{2}\left(1, c_{1 t}\right)$ is negative with $\lim _{n_{t} \rightarrow 0} B_{2}\left(n_{t}, c_{1 t}\right)=0$. For $c_{1 t}<R, B_{2}\left(n_{t}, c_{1 t}\right)$ increases monotonically from 0 to $\beta$ as $n_{t}$ increases from 0 to 1 .

Under $c_{2 t}=c_{2}^{*}\left(c_{1 t}\right)$ the sources of fundamental trader error are the same as in the $\operatorname{REE}\left(n_{t}\right)$ 
market but the incorrect $c_{1 t}$ introduces a new source of error for the market-based traders,

$$
\begin{aligned}
\sigma_{F}^{2}\left(n_{t}, c_{1 t}\right) & =\left((1-\beta)\left(\frac{R}{R-\phi}\right)^{2}+\frac{B_{2}^{2}\left(n_{t}, c_{1 t}\right)}{(R-\phi)^{2}}\right) \sigma_{\epsilon}^{2} \\
\sigma_{M}^{2}\left(n_{t}, c_{1 t}\right) & =\left(\left(\frac{R-c_{1 t} B_{2}\left(n_{t}, c_{1 t}\right)}{R-\phi}\right)^{2}+\frac{B_{2}^{2}\left(n_{t}, c_{1 t}\right)}{(R-\phi)^{2}}\right) \sigma_{\epsilon}^{2}
\end{aligned}
$$

The added term in $\sigma_{M}^{2}$ introduces the possibility that the fundamental information is superior at predicting payoff, earning profit at the expense of the market-based information.

Like the REE $\left(n_{t}\right)$ market, the HSBR market generates expected profits $E\left(\pi_{t}^{F}-\pi_{t}^{M}\right)=\Delta_{t}$ for $n_{t} \in(0,1]$, where

$$
\Delta_{t}=\Delta\left(c_{1 t}, n_{t}\right)=\left(\frac{n_{t}(1-\beta) R+\left(1-n_{t}\right)\left(R-c_{1 t}\right) \kappa}{\left(n_{t} R+\left(1-n_{t}\right)\left(R-c_{1 t}\right) \kappa\right)^{2}}\right)\left(\frac{R}{R-\phi}\right)^{2} \frac{\left(R-c_{1 t}\right) \beta \sigma_{\epsilon}^{2}}{\sigma_{M}^{2}} .
$$

The fundamental traders only profit in the presence of error in the market-based traders' model, as $c_{1 t}$ deviates sufficiently from $\lim _{n_{t} \rightarrow 0} c_{1}^{*}\left(n_{t}\right)=R$.

\subsubsection{Bounded rationality with model-inconsistent beliefs}

A low sophistication boundedly rational (LSBR) population fails to employ $c_{2 t}=c_{2}^{*}\left(c_{1 t}\right)$. For $c_{2 t} \neq c_{2}^{*}\left(c_{1 t}\right), B_{1 t}$ and $B_{2 t}$ are as expressed in (12) and (13). With $B_{1 t} \neq 1$, the market incorrectly prices both $d_{t}$ and $\epsilon_{t+1}$. The market-based traders introduce the mispricing of $d_{t}$ due to their incorrect control for the impact of $d_{t}$ on $p_{t}$. As a consequence, fundamental traders mis-price $d_{t}$ because their belief about the price structure is not consistent with the actual price structure.

\subsubsection{Bounded rationality in conditional variance beliefs}

Another challenge for the traders is how to evaluate the uncertainty associated with forecasting payoff. With $\kappa$ in the price coefficients, correct pricing depends on proportionally appropriate risk-adjusted demand. The ratio $\sigma_{F}^{*}\left(n_{t}\right)^{2} / \sigma_{M}^{*}\left(n_{t}\right)^{2}$ is state dependent and monotonically increasing in $n_{t}$ with $\kappa^{*}\left(n_{t}\right) \in\left[1+(1-\beta) R^{2}, 1+(1-\beta) R^{2} / \beta\right]$. Dangerous mispricing arises as the denominator of $B_{2 t}\left(n_{t}, c_{1 t}\right)$ approaches zero, possibly assisted by $\kappa_{t}>\kappa^{*}\left(n_{t}\right)$.

Both $c_{1 t}>c_{1}^{*}\left(n_{t}\right)$ and $\kappa_{t}>\kappa^{*}\left(n_{t}\right)$ reflect a market in which the actual $n_{t}$ is less than the $n_{t}$ inferred from the market-based trader beliefs (i.e. the market-based traders optimize for an $n_{t}$ larger than actual). From the perspective of the market-based traders, an increase in the 
price is interpreted as an indication of good news about the underlying $\epsilon_{t+1}$, increasing demand. When $c_{1 t}>c_{1}^{*}\left(n_{t}\right)$, the market-based traders overreact causing potentially larger-than-efficient price innovations. ${ }^{10}$ At the extreme, when $n_{t} \rightarrow \tilde{n}\left(c_{1 t}\right)$, this generates substantial mispricing.

The $\operatorname{REE}\left(n_{t}\right)$ market is stabilized by state-dependent determination of $\kappa^{*}\left(n_{t}\right)$. Without knowledge of $n_{t}$, the traders cannot make the correct adjustment. Possible adaptive accommodations for the unknowable $\sigma_{F}^{*}\left(n_{t}\right)$ and $\sigma_{M}^{*}\left(n_{t}\right)$ invite error. Employing $\sigma_{F}^{2}=\sigma_{M}^{2}$, as in Brock and Hommes (1998), or estimated $\hat{\sigma}_{F, t}$ and $\hat{\sigma}_{M, t}$ based on past realized errors, as in the default simulation treatment of Section 3, fix the value of $\kappa_{t}$ to a value that can be vastly inconsistent with the concurrent state. An alternative, considered in the phase-space analysis of Section 2.5.1 and as a Treatment 4 in 3 allows the market-based traders to incorporate information from the current state into their estimate of $\hat{\sigma}_{M, t}$, eliminating the extreme mispricing originating from incorrect beliefs. ${ }^{11}$

\subsection{Evolution}

The HSBR traders who impose $c_{2 t}=c_{2}^{*}\left(c_{1 t}\right)$ remain uncertain of $c_{1 t}$ without knowledge of $n_{t}$. Reasonably, $n_{t}$ is not directly observable. For an $n_{t}$ that is the endogenous product of a dynamic system, the question becomes whether traders can identify the correct $c_{1}^{*}\left(n_{t}\right)$ without directly observing $n_{t}$. This would be the case if, for example, some fixed point $n^{f p}$ of the dynamic system can be identified as consistent with $\operatorname{REE}\left(n_{t}\right)$.

Two processes for governing how popularity evolves in response to performance differentials are considered for how they alter the long run and evolutionary processes of the system. Let innovation population dynamic (IPD) identify the set of processes in which the performance differential determines the innovation in popularity. The example adopted for analysis is the 2-choice version of the more general $K$ choice replicator dynamic (RD) model found in Branch

\footnotetext{
${ }^{10}$ The overreaction can be interpreted as a mis-reading of the information or as a failure to properly account for their own price impact.

${ }^{11}$ The effect is to limit market-based trader demand when they cause too much price deviation by increasing their uncertainty. This is in contrast to the approach taken by Day and Huang (1990) where fundamental traders do not trade when the price is too distant from the fundamental.
} 
and McGough (2008). The model generates the transition equation

$$
n_{t}=g\left(E\left(\pi_{t}^{F}-\pi_{t}^{M}\right), n_{t-1}\right)= \begin{cases}n_{t-1}+r\left(E\left(\pi_{t}^{F}-\pi_{t}^{M}\right)\right)\left(1-n_{t-1}\right) & \text { for } E\left(\pi_{t}^{F}\right) \geq E\left(\pi_{t}^{M}\right) \\ n_{t-1}+r\left(E\left(\pi_{t}^{F}-\pi_{t}^{M}\right)\right) n_{t-1} & \text { for } E\left(\pi_{t}^{F}\right)<E\left(\pi_{t}^{M}\right)\end{cases}
$$

with

$$
r(x)=\tanh (\delta x / 2)
$$

driving the $n_{t}$ process. According to (33), estimates of superior performance by the counterfactual strategy move the population away from the boundary. ${ }^{12}$

Let level population dynamic (LPD) identify the set of processes in which the performance differential determines the level of popularity. The example adopted for analysis is the discrete choice dynamics (DCD) process, employed in Brock and Hommes (1998), which identifies popularity as a direct function of the performance differential,

$$
n_{t}=f\left(E\left(\pi_{t}^{F}-\pi_{t}^{M}\right)\right)=\frac{1}{2}\left(1+\tanh \left(\rho E\left(\pi_{t}^{F}-\pi_{t}^{M}\right) / 2\right)\right) .
$$

Parameters $\delta$ and $\rho$ play similar roles in setting the sensitivity of the trader population to the magnitude of $E\left(\pi_{t}^{F}-\pi_{t}^{M}\right)$. Under the RD process, the anticipated superior strategy attracts adherents from the less successful strategy, consistent with the process described in Grossman and Stiglitz (1980). Under the DCD, $E\left(\pi_{t}^{F}-\pi_{t}^{M}\right)$ maps directly into $n_{t}$ with the superior strategy always employed by the majority of the population.

A fixed point to the entire dynamic system requires the $\operatorname{REE}\left(n_{t}\right)$ solution combined with a fixed point to the population process. The fixed point condition depends on the population regime.

Proposition 1. Given a level population dynamic (LPD) for $n_{t}$, the $R E E\left(n_{t}\right)$ competitive equilibrium has a unique fixed point $n^{f p}$ at which $n^{f p}=f\left(\Delta^{*}\left(n^{f p}\right)\right)$.

Proof. Under the LPD population process, $n_{t}=f\left(E\left(\pi_{t}^{F}-\pi_{t}^{M}\right)\right)$. At the $\operatorname{REE}\left(n_{t}\right), E\left(\pi_{t}^{F}-\pi_{t}^{M}\right)=$ $\Delta^{*}\left(n_{t}\right)$. For $\rho<\infty, f(x)$ is continuous and monotonically increasing in $x$. A fixed point

\footnotetext{
${ }^{12}$ Unlike its biological origins, the RD as employed need not be absorbing at the boundaries as evolution is driven by shifting behavior rather than births and deaths. Parke and Waters (2007) and Guse (2010) preserve the absorbing boundary attribute of RD.
} 


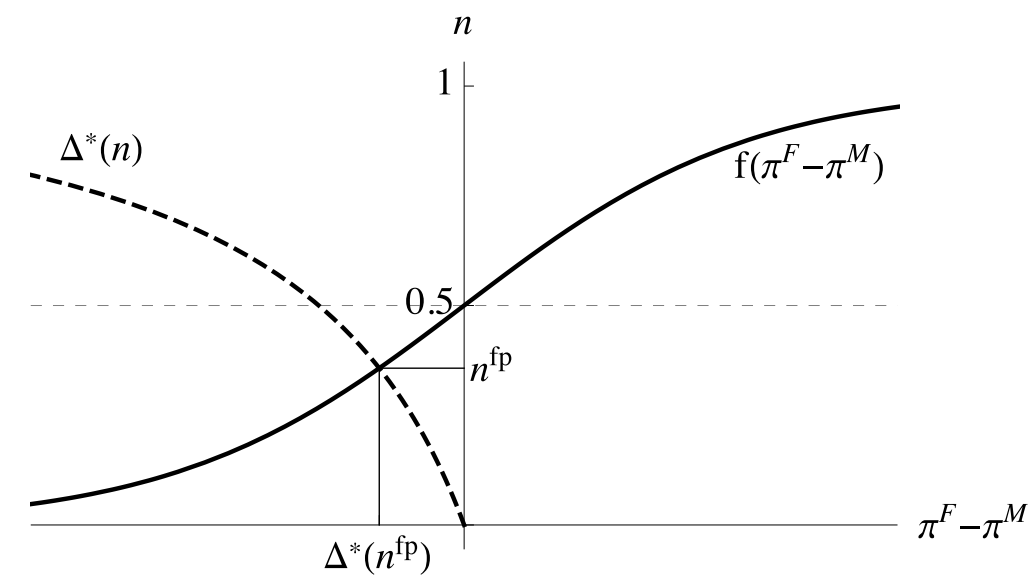

Figure 2: $n^{f p}$ for DCD population dynamics.

solution is $n^{f p}$ such that $n^{f p}=f\left(\Delta^{*}\left(n^{f p}\right)\right)$. Since $\lim _{n_{t} \rightarrow 0} \Delta^{*}\left(n_{t}\right)=0$ and $\Delta^{*}\left(n_{t}\right)$ is monotonically decreasing as $n_{t}$ increases to one, a unique $n^{f p}, 0<n^{f p} \leq 1 / 2$, such that $n^{f p}=f\left(\Delta^{*}\left(n^{f p}\right)\right)$ exists.

Figure 2 captures the existence of the fixed point under the DCD population process. Since the slope of $\left.f(x)\right|_{x=0}$ increases with $\rho$ in Figure 2, the value of $n^{f p} \in(0,1 / 2]$ decreases with increasing $\rho$. At the extremes, $\rho=0$ results in a horizontal $f\left(E\left(\pi^{F}-\pi^{M}\right)\right)$ and $n^{f p}=1 / 2$ while $\rho \rightarrow \infty$ approaches a step function in $f\left(E\left(\pi^{F}-\pi^{M}\right)\right)$ so that $n^{f p} \rightarrow 0$. With $E\left(\pi_{f p}^{F}-\pi_{f p}^{M}\right)<0$, the inferior profits of the fundamental strategy at $n^{f p}$ support the realization of $n^{f p}<1 / 2$. The DCD fixed point is inconsistent with the Grossman and Stiglitz (1980) notion of an equilibrium in which the expected performance differential is zero.

Proposition 2. Given an innovation population dynamic (IPD) for $n_{t}$, the $R E E\left(n_{t}\right)$ competitive equilibrium excludes a fixed point in $n_{t}$.

Proof. Under the IPD population process, the fixed point condition requires the existence of an $n^{f p}$ such that $n^{f p}=g\left(\Delta^{*}\left(n^{f p}\right), n^{f p}\right)$. With $n=g(\Delta, n)$ if and only if $\Delta=0$, the fixed point requires $\Delta^{*}\left(n^{f p}\right)=0$. Since no such $n^{f p}$ exists, there can be no fixed point to the RD population process.

The existence of an REE depends on the existence of a $\left(n^{f p}, c_{1}\right)$ combination for which $n^{f p}=n^{*}\left(c_{1}^{*}\left(n^{f p}\right)\right)$. Such a point does not exist since for $c_{1 t}=c_{1}^{*}\left(n_{t}\right), \Delta^{*}\left(n_{t}\right)<0$ for all $n_{t} \in(0,1]$ and $E\left(\pi_{t}^{F}-\pi_{t}^{M}\right)>0$ for $n_{t}=0$. The Grossman and Stiglitz (1980) discontinuity means that the $n_{t}=0$ boundary is reflecting rather than absorbing. 


\subsection{Learning}

Consider a fixed $n_{t}=n \in(0,1]$ for all $t$. Allow traders to update the market-based model based on empirical observations. Least-squares learning involves a process of updating the coefficients of (7) according to

$$
\begin{aligned}
& \hat{\mathbf{c}}_{t}=\hat{\mathbf{c}}_{t-1}+\lambda_{t}\left(Q_{t}^{-1} x_{t-2}\left(p_{t-1}+d_{t-1}-\hat{\mathbf{c}}_{t-1} x_{t-2}\right)\right)^{\prime} \\
& \hat{Q}_{t}=\hat{Q}_{t-1}+\lambda_{t}\left(x_{t-1} x_{t-1}^{\prime}-\hat{Q}_{t-1}\right)
\end{aligned}
$$

with $\lambda_{t}=1 / t$ and $x_{t}=\left\{1, p_{t}, d_{t}\right\}$. Here, $\hat{\mathbf{c}}_{t}=\left\{\hat{c}_{0 t}, \hat{c}_{1 t}, \hat{c}_{2 t}\right\}$ reflects the time $t$ estimate of the corresponding coefficient of (7) based on the learning algorithm while $\hat{Q}_{t}$ is the estimate of the variance-covariance matrix for $x_{t}$ used in the estimation of $\hat{\mathbf{c}}_{t}$.

Proposition 3. Given a fixed $n, \sigma_{k t}^{2}=\sigma_{k}^{2}\left(n, \mathbf{c}_{t}\right)$, a sequence of market clearing prices $\left\{p_{t}\right\}_{t=0}^{\infty}$, and least-squares updating of beliefs and performance, the REE(n) competitive equilibrium is locally stable.

Proof. See Appendix

By Proposition 3, the self-referencing system of prices and beliefs is locally stable at the $\operatorname{REE}(n)$ under least-squares learning. As the fixed point to the learning process, the elements of $\mathbf{c}^{*}(n)$ are the rational expectations coefficients for the market-based traders so that the least-squares learning process achieves the $\operatorname{REE}(n)$.

The parameters $\lambda_{t}$ regulates the learning process. With $\lambda_{t}=1 / t$, traders update the market-based model consistent with the standard least-squares learning algorithm of Marcet and Sargent (1989b), giving equal weight to each observation. Least-squares learning is a natural choice for the traders given a fixed hidden state variable. The perpetually evolving state of the RD processes can make other parameter updating processes seem reasonable. For $\lambda_{t}=\lambda, 0<\lambda<1$, the traders update with a constant gain by which the contribution of past observations to the current parameter estimate decays exponentially.

Imposing $c_{0 t}=0$ and $c_{2 t}=c_{2}^{*}\left(c_{1 t}\right)$ in the HSBR leaves $c_{1 t}$ as the only estimated parameter of the market-based model. Accordingly, $x_{t}=p_{t}-\phi d_{t} /(R-\phi)$ in (36) and (37).

As the determents of which information to employ, uncertainty regarding the values of $E\left(\pi_{F}\left(n_{t}, c_{1 t}\right)\right)$ and $E\left(\pi_{M}\left(n_{t}, c_{1 t}\right)\right)$ elicits trader accommodation. Let $\hat{\pi}_{t}^{k}$ represent the experience- 
based performance measure associated with type $k$ strategy. At time $t$, the traders can employ $\hat{\pi}_{t-1}^{k}$ as a substitute for $E\left(\pi_{k}\left(n_{t}, c_{1 t}\right)\right)$. With each fundamental trader trading based on idiosyncratic information, $\hat{\pi}_{t-1}^{F}$ is the average of the fundamental population. Each trader must also estimate the $\sigma_{k t}^{2}, k \in\{F, M\}$, appropriate for the model adopted as an input to demand. Consider the updating algorithms

$$
\begin{aligned}
\hat{\pi}_{t}^{k} & =\hat{\pi}_{t-1}^{k}+\mu_{t}\left(\pi_{t-1}^{k}-\hat{\pi}_{t-1}^{k}\right), k=F, M \\
\hat{\sigma}_{k t}^{2} & =\hat{\sigma}_{k t-1}^{2}+\theta_{t}\left(\left(p_{t}+d_{t}-E\left(p_{t}+d_{t} \mid Z_{t-1}^{k}\right)\right)^{2}-\hat{\sigma}_{k t-1}^{2}\right)
\end{aligned}
$$

Like $\lambda_{t}$, the parameters $\theta_{t}$ and $\mu_{t}$ regulate the learning process. Under least-squares learning, with $\theta_{t}=\mu_{t}=1 / t, \hat{\sigma}_{k t}^{2}$ and $\hat{\pi}_{t}^{k}$ are simple sample averages of all past observations. A constant gain biases weight towards the more recent observations.

\subsubsection{Evolution without a fixed point}

A two dimensional phase space analysis in $n_{t}$ and $c_{1 t}$ captures the important drivers of the more complex system represented by equations (1), (10), (33), (36), (37) and (38). Reducing the system down to these two state variables requires imposing the HSBR constraints $c_{0 t}=c_{0}^{*}=0$ and $\hat{c}_{2 t}=c_{2}^{*}\left(\hat{c}_{1 t}\right)$, setting $\mu_{t}=\mu=1$, and assuming $\operatorname{REE}\left(n_{t}\right)$ in the conditional variances $\hat{\sigma}_{t k}^{2}=\sigma_{k}^{2}\left(n_{t}, c_{1 t}\right)$ of $(30)$ and (31) for $k \in\{F, M\}$. The HSBR constraints reduce the marketbased model to a single parameter. The limited memory on performance means that the time $t$ realization of $\pi^{F}\left(\hat{c}_{1 t}, n_{t}\right)-\pi^{M}\left(\hat{c}_{1 t}, n_{t}\right)$ alone identifies $n_{t+1}$ in (38). The conditional variance depends on the current $n_{t}$ and $\hat{c}_{1 t}$ rather than the history-dependent estimate (39)

Market-based trader beliefs are unchanging if $\hat{c}_{1 t}=c_{1}^{*}\left(n_{t}\right)$. As depicted in Figure 3 The function $c_{1}^{*}\left(n_{t}\right)$ is monotonically increasing for $0<n_{t} \leq 1$ with $c_{1}^{*}(n) \rightarrow R$ for $n \rightarrow 0$ and $c_{1}^{*}(1)=R / \beta$.

The population progress is at a steady state if $\Delta\left(\hat{c}_{1 t}, n_{t}\right)=0$. The coefficient $c_{1 t}$ appears twice in the numerator of $\Delta\left(\hat{c}_{1 t}, n_{t}\right)$. Let $c_{1}^{+}\left(n_{t}\right)$ and $c_{1}^{-}$represent the two functions capturing combinations of $\hat{c}_{1 t}$ and $n_{t}$ consistent with $\Delta\left(\hat{c}_{1 t}, n_{t}\right)=0$ in (32). For $0<n_{t} \leq 1$, the former is monotonically increasing and everywhere above $c_{1}^{*}\left(n_{t}\right)$,

$$
c_{1}^{+}\left(n_{t}\right)=R\left(1+(1-\beta) \frac{n_{t}}{\left(1-n_{t}\right) \kappa}\right) .
$$




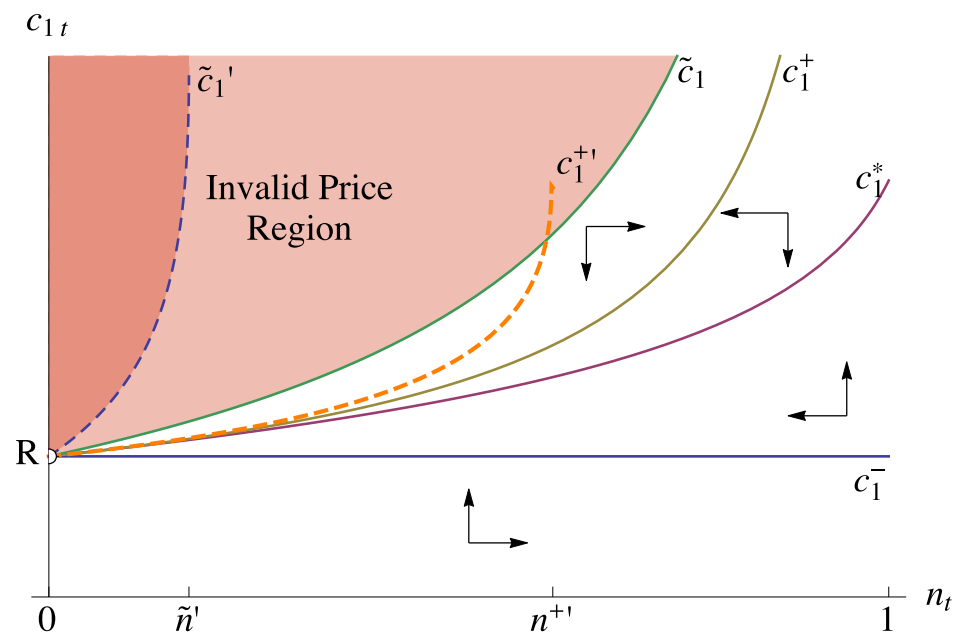

Figure 3: Phase space in $n_{t}$ and $\hat{c}_{1 t}$ for the $\mathrm{RD}$ population process. $c_{1}^{*}\left(n_{t}\right)$ is the $\operatorname{REE}\left(n_{t}\right)$ value of $\hat{c}_{1 t}$ and the attractor to the learning process for a given $n_{t}$. For $c_{1}^{-}<\hat{c}_{1 t}<c_{1}^{+}\left(n_{t}\right)$ the marketbased model is sufficiently accurate to earn profits at the expense of the fundamental strategy, leading to a decline in $n_{t}$. For $\hat{c}_{1 t}<c_{1}^{-}$and for $c_{1}^{+}\left(n_{t}\right)<\hat{c}_{1 t}<\tilde{c}_{1}\left(n_{t}\right)$ the fundamental strategy dominates the market-based strategy so that from these regions $n_{t}$ is increasing. Above $\tilde{c}_{1}\left(n_{t}\right)$, the aggregate demand curve for the risky security is upward sloping and no positive price exists to clear the market. The dashed lines reflect an alternate specification for which the currentperiod implication of $\hat{c}_{1 t} \neq c_{1}^{*}\left(n_{t}\right)$ is recognized when calculating the market-based model error. The market is more tolerant of error, as reflected in ${c_{1}^{+\prime}}^{\prime}$ and $\tilde{c}_{1}^{\prime}$, when market-based trader are increasingly uncertain in the face of large price deviations (developed in Section 2.3.3).

The latter is a constant, $c_{1}^{-}=R$, located below $c_{1}^{*}\left(n_{t}\right)$. Expected profits are zero at $\hat{c}_{1 t}=c_{1}^{+}\left(n_{t}\right)$ because the resulting market clearing price is the efficient market price, $p_{t}^{1}$, at which expected profits are zero regardless of the individual trader's position taken in the market. Expected profits are zero at $\hat{c}_{1 t}=c_{1}^{-}\left(n_{t}\right)$ because the market traders expect the risky asset to offer the same return as the risk-free bond and thus there is no trading at the market clearing price.

A third relevant function included in the phase space is $\tilde{c}_{1}\left(n_{t}\right)$. The expression $n_{t} R+$ $\left(1-n_{t}\right)\left(R-\hat{c}_{1 t}\right) \kappa_{t}$ appears in the denominator of the two pricing coefficients, $B_{1}\left(\hat{c}_{1 t}, n_{t}\right)$ and $B_{2}\left(\hat{c}_{1 t}, n_{t}\right)$ as well as the denominator of $\Delta\left(\hat{c}_{1 t}, n_{t}\right)$. The negative of the expression is the slope of the risky asset's aggregate demand function so that when it is zero the market demand function is horizontal and different from zero, producing an infinite market clearing price (based on a zero net supply). Let $\tilde{c}_{1}\left(n_{t}\right)$ be the function

$$
\tilde{c}_{1}\left(n_{t}\right)=R\left(1+\frac{n_{t}}{\left(1-n_{t}\right) \kappa}\right)
$$

producing $n_{t} R+\left(1-n_{t}\right)\left(R-\tilde{c}_{1}\left(n_{t}\right)\right) \kappa=0$. This is the inverse function of $\tilde{n}\left(c_{1 t}\right)$. For $0<$ 
$n_{t} \leq 1, \tilde{c}_{1}\left(n_{t}\right)$ is monotonically increasing and everywhere above $c_{1}^{+}\left(n_{t}\right)$. Combinations of $c_{1 t}$ and $n_{t}$ approaching the function from below or from the right generate $p_{t}\left(c_{1 t}, n_{t}\right) \rightarrow \infty$ and $\Delta\left(\hat{c}_{1 t}, n_{t}\right) \rightarrow \infty$.

Above $\tilde{c}_{1}\left(n_{t}\right)$, the combination of $n_{t}$ and $\hat{c}_{1 t}$ do not allow for a reasonable market clearing price. The precarious nature of the market in the vicinity of $\tilde{c}_{1}\left(n_{t}\right)$ is the consequence of the excessive influence of the market-based traders. As a group, they have an upward sloping demand function in price. At $\hat{c}_{1 t}=c_{1}^{*}\left(n_{t}\right)$, the market-based model correctly accounts for the influence of the market-based trader population on the price. As a consequence, the aggregate demand for the risky asset remains downward sloping in $p_{t}$. For $\hat{c}_{1 t}>c_{1}^{*}\left(n_{t}\right)$, the market-based model projects too large an $\epsilon_{t+1}$ based on the observed $p_{t}$. The market-based traders thus take too large a position relative to the underlying reality. For $\hat{c}_{1 t}>\tilde{c}_{1}\left(n_{t}\right)$, the position produces an upward-sloping aggregate market demand function. ${ }^{13}$

The traders themselves cannot be relied upon to recognize dangerous market conditions introduced by their own beliefs. Implicit in the trader's use of $\hat{c}_{1 t}$ is that it is a reasonable approximation of $c_{1}^{*}\left(n_{t}\right)$ for the current unobserved $n_{t}$. For any $\hat{c}_{1 t} \in(R, R / \beta]$ there exists $n_{1}$ and $n_{2}, 0<n_{1}<n_{2} \leq 1$ for which $\hat{c}_{1 t}=\tilde{c}_{1}\left(n_{1}\right)$ and $\hat{c}_{1 t}=c_{1}^{*}\left(n_{2}\right)$. The market-based traders' belief that $c_{1 t}=\hat{c}_{1 t}$ is reasonable if the unobserved $n_{t}$ is near $n_{2}$ but disastrously wrong, generating substantial mispricing, if $n_{t}$ is near $n_{1}$. The greater distances between $c_{1}^{*}\left(n_{t}\right)$ and $c_{1}^{+}\left(n_{t}\right)$ and between $c_{1}^{+}\left(n_{t}\right)$ and $\tilde{c}_{1}\left(n_{t}\right)$ as $n_{t}$ increases reflect a market more tolerant of trader error.

Given $n_{t}, c_{1}^{*}\left(n_{t}\right)$ is an attractor for $\hat{c}_{1 t}$. For $\hat{c}_{1 t}$ between $c_{1}^{-}\left(n_{t}\right)$ and $c_{1}^{+}\left(n_{t}\right), E\left(\Delta\left(\hat{c}_{1 t}, n_{t}\right)\right)<0$ so that $n_{t}$ tends to decline. In this range, the market-based model, while not necessarily perfectly correct for extracting information from the price, is more accurate than the average fundamental trader relying on a noisy signal. Outside this range, with $\hat{c}_{1 t}<c_{1}^{-}$or $c_{1}^{+}\left(n_{t}\right)<\hat{c}_{1 t}<\tilde{c}_{1}\left(n_{t}\right)$, the inaccuracy in the market-based model is large enough that the user of the fundamental information can expect to earn profits at the expense of the market-based traders and therefore $n_{t}$ tends to increase in this region.

All four functions of the phase space radiate out from the point $n_{t}=0$ and $\hat{c}_{1 t}=R$ but because of the discontinuity at $n_{t}=0$, none take a value of $R$ at $n_{t}=0$. Therefore, though the

\footnotetext{
${ }^{13} \mathrm{As}$ an alternate interpretation, for $\hat{c}_{1 t}>c_{1}^{*}\left(n_{t}\right)$, the market-based model can be seen as underestimating the influence of the market-based traders on the price since, for $\hat{c}_{1 t}<R / \beta$, there exists $n>n_{t}$ such that $\hat{c}_{1 t}=c_{1}^{*}(n)$.
} 


\begin{tabular}{|c|c|c|c|c|c|c|c|c|}
\hline Treatment & Figures & $n_{t}$ process & $\rho$ & $\delta$ & $\lambda$ & $\mu$ & $c_{2 t}$ & $\sigma_{t}^{k}$ \\
\hline \hline 0 & - & $n_{t}=1$ & - & - & - & - & - & $\sigma_{F}^{*}(1)$ \\
\hline 1 & $4 \& 5$ & DCD & 10 & - & $1 / t$ & $1 / t$ & $c_{2}^{*}\left(\hat{c}_{1 t}\right)$ & $\hat{\sigma}_{t}^{k}$ \\
\hline 2 & - & DCD & 1 & - & $1 / t$ & 1 & $c_{2}^{*}\left(\hat{c}_{1 t}\right)$ & $\hat{\sigma}_{t}^{k}$ \\
\hline 3 & 6 & $\mathrm{RD}$ & - & 0.01 & $1 / t$ & $1 / t$ & $c_{2}^{*}\left(\hat{c}_{1 t}\right)$ & $\hat{\sigma}_{t}^{k}$ \\
\hline 4 & 7 & $\mathrm{RD}$ & - & 1 & $1 / t$ & $1 / t$ & $c_{2}^{*}\left(\hat{c}_{1 t}\right)$ & $\hat{\sigma}_{t}^{k}$ \\
\hline 5 & 8 & $\mathrm{RD}$ & - & 0.05 & $1 / t$ & 1 & $c_{2}^{*}\left(\hat{c}_{1 t}\right)$ & $\sigma^{*}\left(n_{t}\right)$ \\
\hline 6 & 9 & $\mathrm{RD}$ & - & 0.08 & 0.01 & 0.00001 & $c_{2}^{*}\left(\hat{c}_{1 t}\right)$ & $\sigma\left(n_{t}, c_{1 t}\right)$ \\
\hline 7 & 10 & $\mathrm{RD}$ & - & 0.01 & $1 / t$ & $1 / t$ & $\hat{c}_{2 t}$ & $\hat{\sigma}_{t}^{k}$ \\
\hline
\end{tabular}

Table 1: Model treatments. Common to all treatments are the parameters $R=1.02, \phi=0.5$, $\sigma_{\epsilon}=\sigma_{e}=1 \Rightarrow \beta=1 / 2, T=500,000$. The same dividend stream is used in each simulation.

four functions come arbitrarily close, they never intersect. The failure of $c_{1}^{*}\left(n_{t}\right)$ to intersect with either $c_{1}^{-}\left(n_{t}\right)$ or $c_{1}^{+}\left(n_{t}\right)$ graphically captures the absence of a fixed point to the RD dynamic system.

\section{Simulations}

Computational analysis reveals properties of the market model not accessible using analytical tools. Simulations facilitate analysis of the impact of different implementations of bounded rationality. Table 1 reports the parameters employed in the different treatments of the model. As a reference, Treatment 0 is the market populated with only fundamental traders. Treatments 1-6 include adaptive selection between fundamental and market-based information. Popularity of information evolves according to the DCD of Brock and Hommes (1998) in Treatment 1 while Treatments 2-6 consider different forms of bounded rationality under the RD evolutionary process.

All simulations share a starting value, $n_{0}=0.75$ and the parameter values $R=1.02, \phi=0.5$, and $\sigma_{\epsilon}=\sigma_{e}=1$ so that $\beta=1 / 2$. Pre-simulation learning on the market-based model takes place on 200 observations generated using a fixed $n_{t}=n_{0}$. At these parameters, a standard deviation in $\left(p_{t}^{F}-p_{t}^{1}\right)$ of 0.96 .

Figures 4 through 10 display examples of the evolution of endogenous parameters typical of the treatment. To aid direct comparison, each figure is based on the same underlying randomly generated $\left\{d_{t}\right\}_{1}^{T}$ series. Included in each figure is a frame plotting

$$
p_{t}-p_{t}^{1}=\frac{1}{R-\phi}\left(\left(B_{1 t}-1\right) \phi d_{t}+\left(B_{2 t}-1\right) \varepsilon_{t+1}\right) .
$$



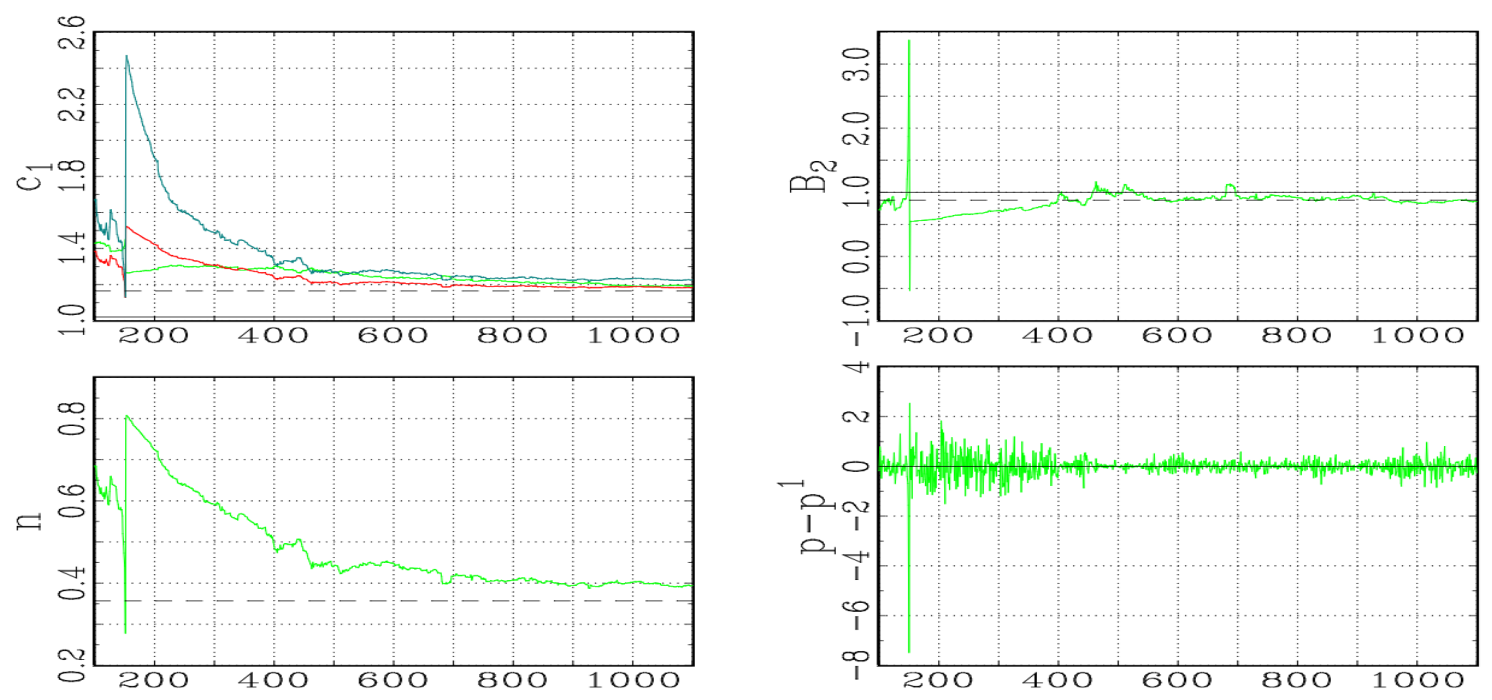

Figure 4: DCD produces convergence towards a $\operatorname{REE}\left(n^{f p}\right)$ fixed point with $n^{f p}=0.357$. Top left plots $c_{1 t}$ (green), $c_{1}^{*}\left(n_{t}\right)$ (red), and $c_{1 t}^{+}\left(n_{t}\right)$ (cyan). Top right plots $B_{2 t}$ with a solid line at 1 . Lower left plots $n_{t}$. Lower right plots $p_{t}-p_{t}^{1}$. In all frames, dashed lines indicate fixed point values, $c_{1}^{*}\left(n^{f p}\right), B_{2}^{*}\left(n^{f p}\right)$, and $n^{f p}$ as appropriate.

The difference captures deviation from the strong-form efficient price so that $\left|p_{t}-p_{t}^{1}\right|$ measures market inefficiency.

\subsection{Level population dynamics}

The local stability of the fixed point under the DCD implementation of a LPD is assured if the traders employ $\mu_{t}=1 / t$ in their performance updating. Figure 4 shows the early convergence of the system under Treatment 1 towards the fixed point value of the respective parameter. Figure 5 shows the asymptotic properties of the convergence. The early evolution includes periods of high volatility in the pricing error each time $\hat{c}_{1 t}>c_{1}^{+}\left(n_{t}\right)$. Asymptotically, the variance of the pricing error appears uniform as $\hat{c}_{1 t} \rightarrow c_{1}^{*}\left(n^{f p}\right)$.

Increasing the IOC parameter $\rho$ decreases $n^{f p}$, reducing the distance between $\tilde{c}_{1}\left(n^{f p}\right)$, $c_{1}^{+}\left(n^{f p}\right), c_{1}^{*}\left(n^{f p}\right)$, and $c_{1}^{-}\left(n^{f p}\right)$. This slows convergence in achieving $n_{t} \approx n^{f p}$ because the greater market sensitivity to erroneous beliefs produces greater price deviations, but otherwise leave the process unaffected.

Similar to increasing $\rho$, shortening memory of past performance also generates large swings in $n_{t}$. The difference is that the swings do not decrease with the accumulation of experience. Without the tempering of response that comes with the least-squares accumulation of knowl- 

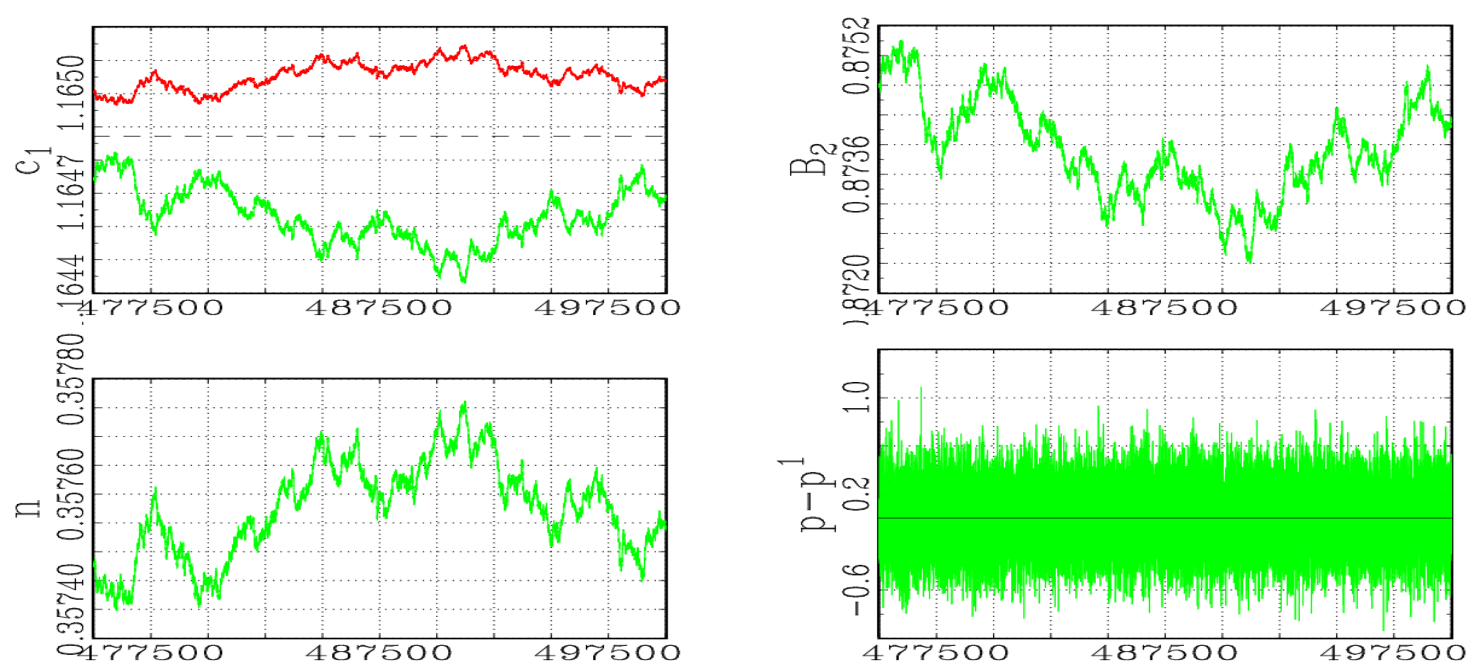

Figure 5: DCD asymptotic behavior around a $\operatorname{REE}\left(n^{f p}\right)$ fixed point with $n^{f p}=0.357$. Top left plots $\hat{c}_{1 t}$ (green) and $c_{1}^{*}\left(n_{t}\right)$ (red). Top right plots $B_{2 t}$ with a solid line at 1 . Lower left plots $n_{t}$. Lower right plots $p_{t}-p_{t}^{1}$. In all frames, dashed lines indicate fixed point values, $c_{1}^{*}\left(n^{f p}\right)$, $B_{2}^{*}\left(n^{f p}\right)$, and $n^{f p}$ as appropriate.

edge, the traders are incapable of preventing the low realizations of $n_{t}$ that put the market in the invalid price region. To obtain convergence in Treatment 2 with no performance memory past the most recent observation requires also dampening the population's IOC.

\subsection{Innovation population dynamics}

The RD process offers a point of attraction at $n_{t}=0$ and $\hat{c}_{1 t}=R$ but not a fixed point. If the system were able to travel along $c_{1}^{*}\left(n_{t}\right)$ as $n_{t} \rightarrow 0$, then the market would produce increasing price efficiency with $p_{t}-p_{t}^{1} \rightarrow 0$.

\subsubsection{Baseline}

The baseline RD setting of Treatment 3 imposes the HSBR conditions on market-based trader behavior employing $c_{2 t}=c_{2}^{*}\left(\hat{c}_{1 t}\right)$. The baseline also employs the long memory of least-squares learning with $\lambda_{t}, \mu_{t}$, and $\theta_{t}$ all set to $1 / t$. Additionally, a low $\delta$ produces a slow evolution in the population towards the higher performing strategy. These features make the baseline setting conducive to asymptotic convergence towards the point of attraction. Observed in Figure 6, the system adheres closely to $c_{1}^{*}\left(n_{t}\right)$ as $n_{t} \rightarrow 0$. The estimated $\hat{c}_{1 t}$ remains well below $\tilde{c}_{1}\left(n_{t}\right)$, also included in the plot. Despite this apparent success in convergence, the system fails to produce 

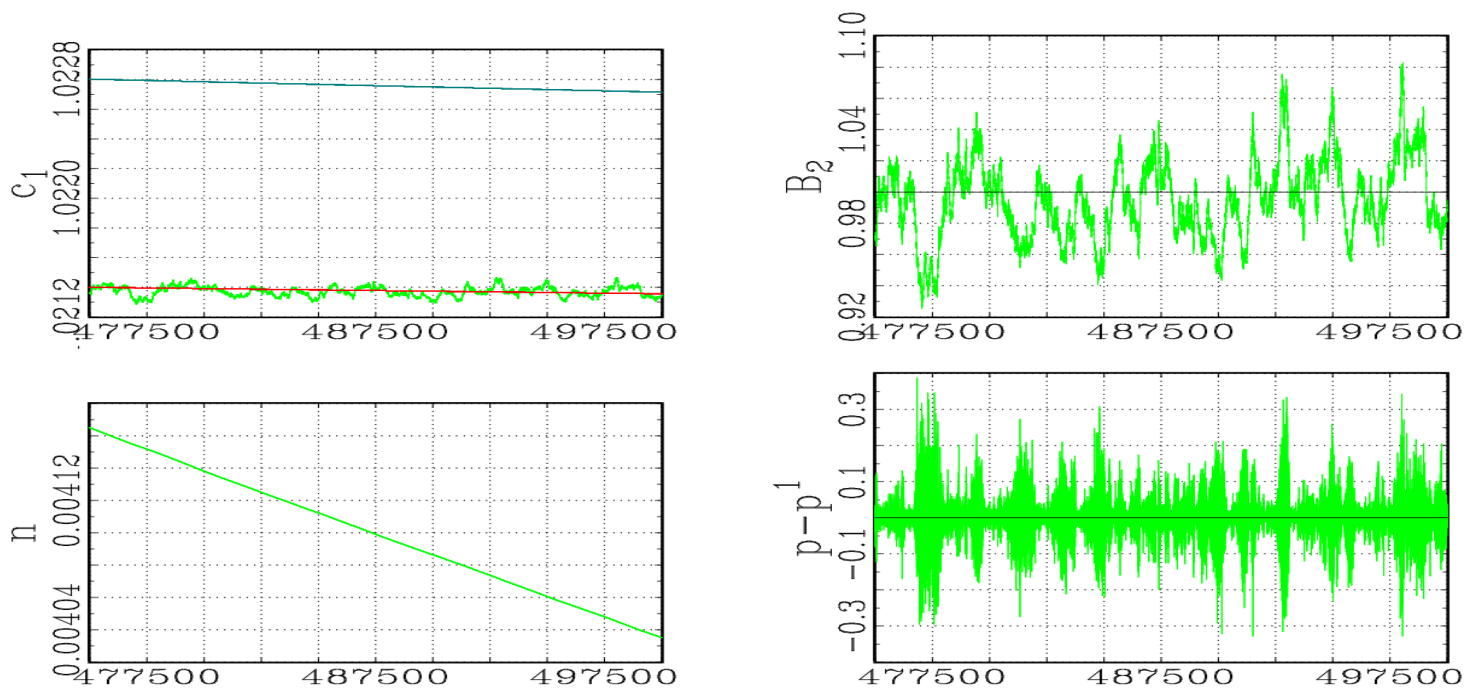

Figure 6: Baseline RD produces smooth convergence $n_{t} \rightarrow 0$ with $\hat{c}_{1 t} \rightarrow c_{1}^{*}\left(n_{t}\right)$. Top left plots $\hat{c}_{1 t}$ (green), $c_{1}^{*}\left(n_{t}\right)$ (red), and $\tilde{c}_{1 t}\left(n_{t}\right)$ (blue). Top right plots $B_{2 t}$ with a solid line at 1 . Lower left plots $n_{t}$. Lower right plots $p_{t}-p_{t}^{1}$.

$p_{t}-p_{t}^{1} \rightarrow 0$. The system instead generates clustered volatility in the pricing error with no indication of increased accuracy over time. The magnitude of the pricing errors coincide with the magnitude of deviation in $B_{2 t}$ from one. The $B_{2 t}$ deviations, driven by deviations in $\hat{c}_{1 t}$ from $c_{1}^{*}\left(n_{t}\right)$, are not independent across time but instead produce a time-series with a highly persistent estimated $\mathrm{AR}(1)$ coefficient of $0.998 .^{14}$

\subsubsection{Responsiveness}

Increasing $\delta$ generates fairly regular oscillations in $n_{t}$ while maintaining an underlying process of convergence towards the point of attraction. Figure 7 from Treatment 4 captures this phenomenon. In contrast to the baseline, the swings in $c_{1}^{*}\left(n_{t}\right)$ are larger than the variance in $c_{1 t}$. The highly responsive population produces exaggerated changes in the relative popularity of the two strategies. These changes outpace the slow improvement in $\hat{c}_{1 t}$ as $t$ becomes large.

Major price disruptions occur when there is a mis-match between $\hat{c}_{1 t}$ and $n_{t}$. The swings produced by a large $\delta$ would seem to invite such outcomes but instances fail to materialize. Convergence continues without major price disruptions because the system self-regulates the rate of decline in $n_{t}$ so that it does not outpace the rate of adjustment in $\hat{c}_{1 t}$. Also, the incremental changes in $n_{t}$ within the cycles are relatively small, so that the system delivers

\footnotetext{
${ }^{14}$ These observations and further analysis of the Baseline setting can be found in Goldbaum (2006)
} 

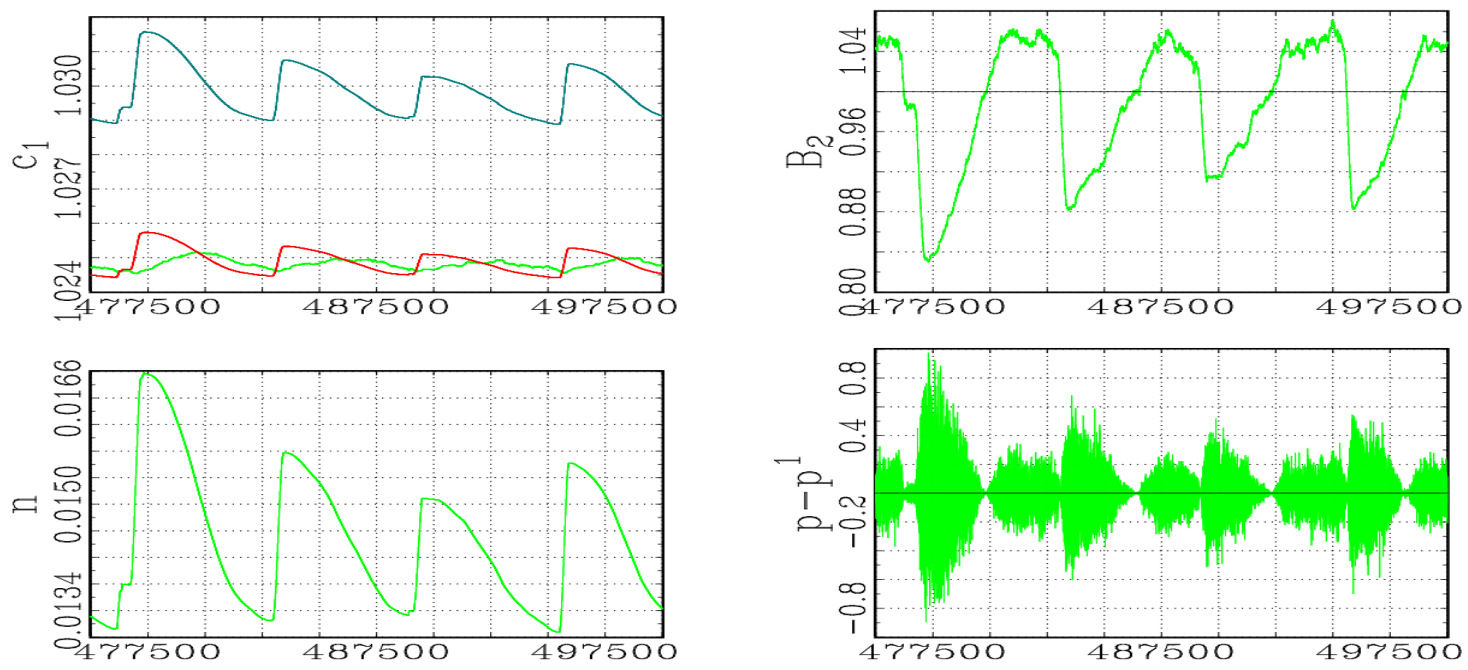

Figure 7: RD with high sensitivity to performance, with $\delta=1$, produces oscillations in $n_{t}$ overlaying its general decreasing trend. Top left plots $\hat{c}_{1 t}$ (green), $c_{1}^{*}\left(n_{t}\right)$ (red), and $\tilde{c}_{1 t}\left(n_{t}\right)$ (blue). Top right plots $B_{2 t}$ with a solid line at 1 . Lower left plots $n_{t}$. Lower right plots $p_{t}-p_{t}^{1}$.

feedback of the rising inconsistency between believes and $n_{t}$ through the profits awarded to the fundamental traders without $n_{t}$ ever getting too far out of line with beliefs.

\subsubsection{Memory in performance}

Treatment 5 presented in Figure 8 substitutes $\mu_{t}=1$ for the long memory of $\mu_{t}=1 / t$. With this change, the treatment closely resembles the model analyzed using the phase space presented in Figure $3 .^{15}$ Contrary to the implied convergence of the phase space, short memory halts the convergence of $n_{t}$ towards zero, with $n_{t}$ in this case hovering around 0.39. Regardless of the quality of information, payoffs are not perfectly forecastable. With a short memory, profit realizations from the unpredicted $\epsilon_{t+2}$ component of $p_{t+1}$ generate large incremental movement in $n_{t}$ around a stable $\hat{c}_{1 t}$. This movement undermines the progression in learning $\hat{c}_{1 t}$ and ultimately the convergence of $n_{t}$. With large jumps in $n_{t}$, incompatibility between $n_{t}$ and $\hat{c}_{1 t}$ arise without prior performance feedback that could prevent the over-use of the market-based model.

The stabilization of the system around a fixed $n$ gives the system the appearance of possessing a fixed point in the underlying dynamic system, similar to that produced by a LPD process.

\footnotetext{
${ }^{15}$ To make the comparison complete, and with no discernible impact on the simulations, the traders measure conditional variance using (22) and (23) rather than the experience-driven (39).
} 

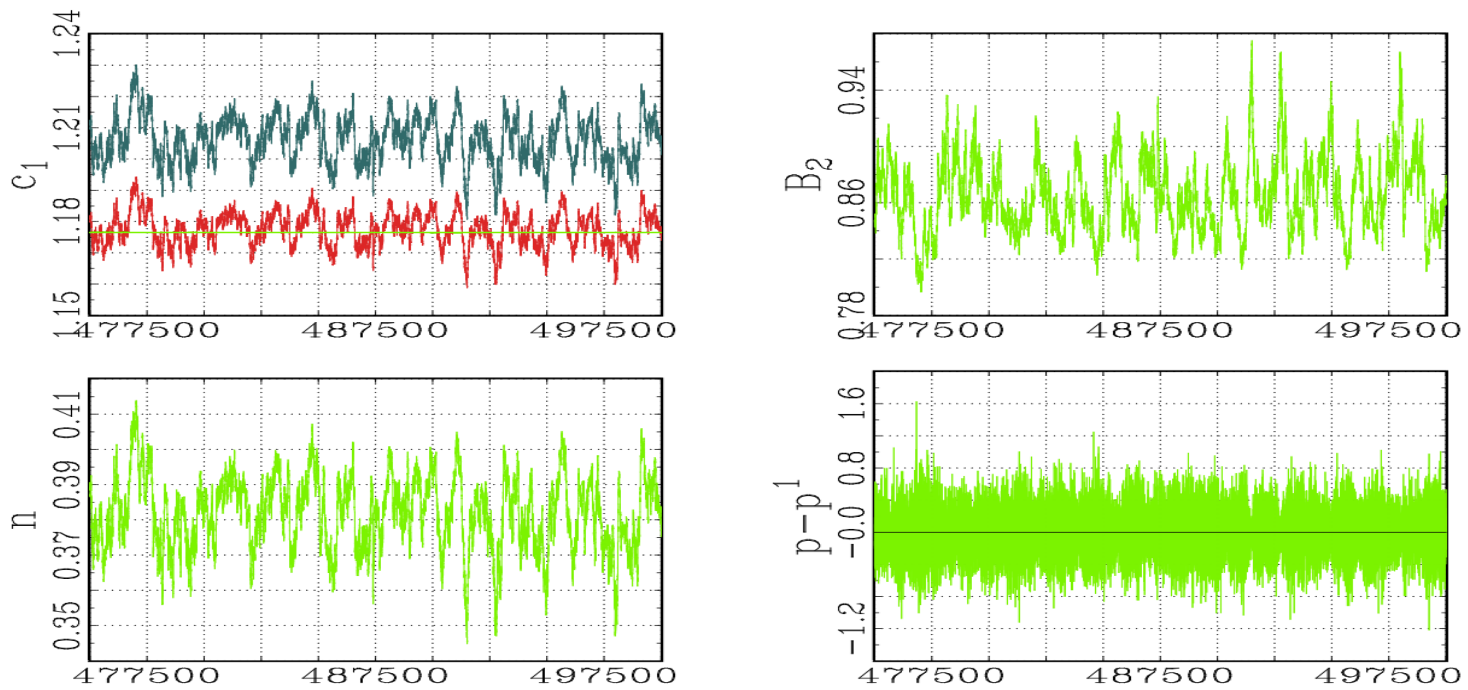

Figure 8: RD with $\mu_{t}=1$ stabilizes $n$ at a value above zero. The estimate $\hat{c}_{1 t}$ is stable over time while $c_{1}^{*}\left(n_{t}\right)$ fluctuates rapidly with the fluctuations in $n_{t}$. Top left plots $\hat{c}_{1 t}$ (green), $c_{1}^{*}\left(n_{t}\right)$ (red), and $c_{1 t}^{+}\left(n_{t}\right)$ (cyan). Top right plots $B_{2 t}$ with a solid line at 1 . Lower left plots $n_{t}$. Lower right plots $p_{t}-p_{t}^{1}$.

\subsubsection{Memory in model}

A constant gain in the updating of the market-based model parameters ensures persistent error in beliefs. For Treatment 6 with $\lambda_{t}=0.01$, Figure 9 reveals that after a period of learning, $\hat{c}_{1 t}$ settles into a stable distribution relative to $c_{1}^{*}\left(n_{t}\right)$, moving over time to track the slow evolution in $c_{1}^{*}\left(n_{t}\right)$. For sufficiently large $n_{t}$, the narrow distribution in $\hat{c}_{1 t}$ favors the market-based model. The constant gain becomes a liability as $n_{t}$ converges towards zero, the distribution in $\hat{c}_{1 t}$ is at some point too wide to remain between the narrowing profitable range bounded by $c_{1}^{-}$and $c_{1}^{+}\left(n_{t}\right)$. The resulting mispricing rewards the fundamental model, reversing the progress in $n_{t}$. The measured $\hat{\pi}^{F}-\hat{\pi}^{M}$ remains positive for some time after the return to near-fundamental pricing until the accumulation of small profits earned by the market-based strategy outweighs the memory of the substantial fundamental trader profit earned during the period of mispricing, producing the cycles observed in Figure 9.

\subsection{5 $\operatorname{REE}\left(n_{t}\right)$ conditions}

The less sophisticated traders under the assumptions of the LSBR market estimate both $c_{1 t}$ and $c_{2 t}$ through the learning process of (36) and (37) rather than impose $c_{2 t}=c_{2}^{*}\left(\hat{c}_{1 t}\right)$. Recall that with $B_{1 t} \neq 1$ this introduces error in the pricing of the $d_{t}$ component of price by both trader 

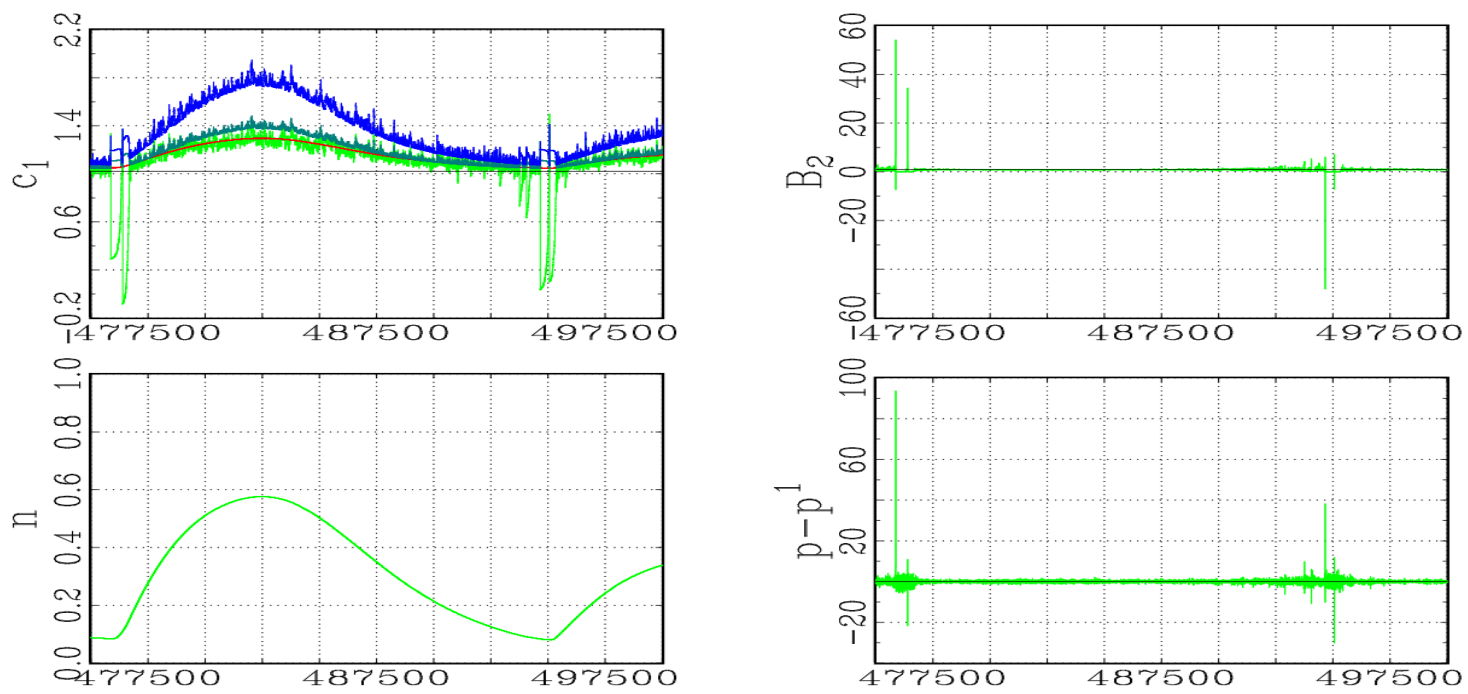

Figure 9: RD with $\lambda_{t}=0.01$ generating small but consistent model error that produces long periods of near efficient pricing with inevitable bursts of mispricing. Top left plots $\hat{c}_{1 t}$ (green), $c_{1}^{*}\left(n_{t}\right)(\mathrm{red}), c_{1 t}^{+}\left(n_{t}\right)$ (cyan), and $\tilde{c}_{1 t}\left(n_{t}\right)$ (blue). Top right plots $B_{2 t}$ with a solid line at 1 . Lower left plots $n_{t}$. Lower right plots $p_{t}-p_{t}^{1}$.

populations (for different reasons) as reflected in (15) and (14).

Figure 10 for Treatment 7 includes frames for $\hat{c}_{2 t}$ on the left and of $B_{1 t}$ on the right. The setting preserves the steady decline in $n_{t}$ suggesting continued improved accuracy in the marketbased model, despite the need to estimate two parameters, with only minimal hindrance.

\subsection{Autocorrelations}

For ret $_{t}=\left(p_{t+1}+d_{t+1}-p_{t}\right) / p_{t}, c_{2 t}=c_{2}^{*}\left(c_{1 t}\right)$ ensures returns depend on the value of $B_{2},{ }^{16}$

$$
\text { ret }_{t} \begin{cases}=(R-1)+\left(\frac{1}{R-\phi}\right) \frac{R \epsilon_{t+1}}{p_{t}} & B_{2}=0 \\ =(R-1)+\left(\frac{1}{R-\phi}\right) \frac{\epsilon_{t+2}}{p_{t}} & B_{2}=1 \\ \approx(R-1)+\left(\frac{1}{R-\phi}\right) \frac{\left(R-B_{2 t}\right) \epsilon_{t+1}+B_{2 t+1} \epsilon_{t+2}}{p_{t}} & B_{2}>0, B_{2} \neq 1 .\end{cases}
$$

There is no inter-temporal correlations in the return structure if $B_{2}=0$ or 1 . Otherwise, the return to time $t$ investment is a function of $\epsilon_{t+1}$ and $\epsilon_{t+2}$, ensuring correlation only in one-period lagged returns so that returns are MA(1).

From (42), the price coefficients $B_{1 t}$ and $B_{2 t}$ each represents a source of inefficiency acting on orthogonal components of the price. The HSBR $B_{1 t}=1$, producing zero for the first term

\footnotetext{
${ }^{16}$ See Appendix B for the derivation.
} 

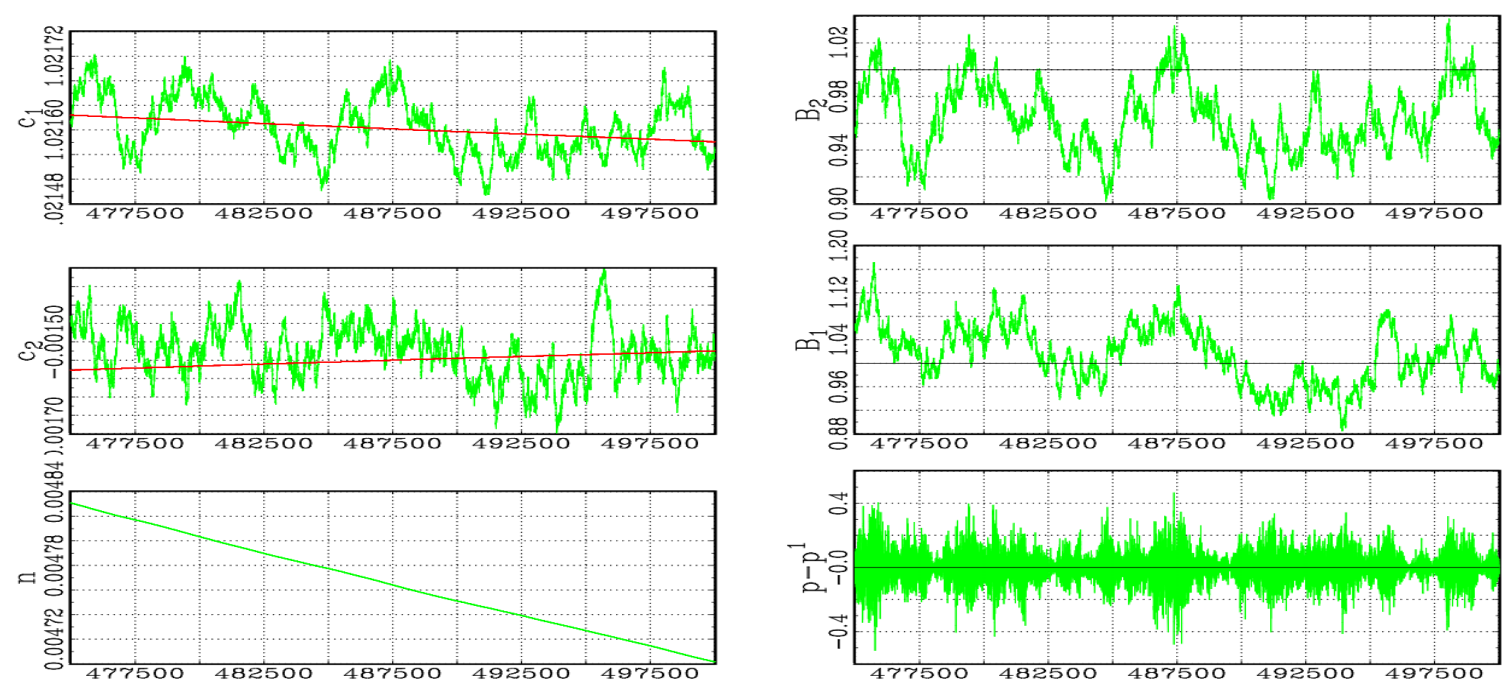

Figure 10: RD with $\hat{c}_{2 t}$ allowed to differ from $c_{2}^{*}\left(\hat{c}_{1 t}\right)$, producing error in the pricing of observable and unobservable components of price. Top left plots $\hat{c}_{1 t}$ (green) and $c_{1}^{*}\left(n_{t}\right)$ (red). Top right plots $B_{2 t}$ with a solid line at 1 . Middle left plots $\hat{c}_{2 t}$ (green) and $c_{2}^{*}\left(n_{t}\right)$ (red). Middle right plots $B_{1 t}$. Lower left plots $n_{t}$. Lower right plots $p_{t}-p_{t}^{1}$.

of (42). To generate $B_{2}^{*}\left(n_{t}\right) \rightarrow 1$ in the second term additionally requires correct market trader beliefs with $\hat{c}_{1 t}=c_{1}^{*}\left(n_{t}\right)$ and a negligible presence of fundamental traders with $n_{t} \rightarrow 0$. As reference, a market populated by only fundamental traders (also with $B_{1 t}=1$ ) produces price that is iid in its deviation from efficiency,

$$
p_{t}^{F}-p_{t}^{1}=-\left(\frac{1-\beta}{R-\phi}\right) \epsilon_{t+1}
$$

The plots of $p_{t}-p_{t}^{1}$ suggest otherwise for the Treatment markets. In particular, visual analysis of Treatments 3-7 suggest the presence of auto-correlative patterns in the absolute pricing error.

Table 2 reports the one-period lag correlation as measured in the final 50,000 periods of each model treatment. The noisy signal leads its recipient fundamental trader to combine current public information with the private signal, resulting in autocorrelated returns in the fundamental-trader-only market. Those treatments with a persistent population of fundamental traders also exhibits autocorrelation in returns as the price continues to reflect current and future information. Treatments 1 and 5 both stabilize with roughly $35 \%$ fundamental traders. Though the reasons for this differ, both produce an autocorrelation in returns of 0.15 . Treatment 6 , with its cycles of $n_{t}$ ranging from 0.08 to 0.58 , generates very little lag correlation. Treatments 3 , 4, and 7 feature market-based traders capable of extracting profitable information even though 


\begin{tabular}{|c|c|c|c|c|c|c|}
\cline { 4 - 6 } & \multicolumn{3}{c|}{ 1-period lag correlations } \\
\hline Treatment & Learning & $n_{t}$ process & $n_{T}$ & Returns & Price Error & $\mid$ Price Error $\mid$ \\
\hline \hline 0 & F traders only & - & 1 & $0.39^{2}$ & $0.00^{2}$ & $0.00^{2}$ \\
\hline 1 & LS & DCD & 0.358 & $0.14^{2}$ & $0.00^{2}$ & $0.00^{2}$ \\
\hline 3 & LS & slow RD & 0.004 & $0.00^{2}$ & $0.00^{2}$ & $0.40^{3}$ \\
\hline 4 & LS & fast RD & 0.013 & $0.00^{2}$ & $0.00^{2}$ & $0.32^{3}$ \\
\hline 5 & Constant gains in $\hat{\pi}^{e}$ & RD & 0.374 & $0.15^{2}$ & $0.00^{2}$ & $0.18^{3}$ \\
\hline 6 & Constant gains in $\hat{c}$ & RD & $0.08-0.58^{1}$ & $0.01^{2}$ & $0.05^{2}$ & $0.37^{4}$ \\
\hline 7 & LS, free $c_{2 t}$ & RD & 0.005 & $0.00^{2}$ & $0.48^{3}$ & $0.48^{4}$ \\
\hline
\end{tabular}

Table 2: Model variations and lag correlations. Lag correlations measured in periods $t \in$ [450000, 500000]. ${ }^{1} n_{t}$ range over sampled $t .{ }^{2}$ zero lag correlations for lags greater than $1 .{ }^{3}$ lag correlation exhibits a slow decay as lags increases. ${ }^{4} 35 \%$ drop in lag correlation from 1 to 2 lags, slow decay thereafter.

fundamental traders represent $1 \%$ of the population or less. The price is close to fully efficient, eliminating all lag correlation in the returns.

Price efficiency and the absence of structure in returns is achieved at the expense of an introduced lag correlation structure in the absolute pricing error. With the asymptotically small population of fundamental traders, even small error in the market-based traders' beliefs produces pricing errors, the magnitude of which persists as long as does the error in beliefs. Substantial fundamental populations in Treatment 1 overwhelm the impact of market-based trader error on price. This is not true in Treatment 5 where, despite a slightly greater number of fundamental traders, movements in $n_{t}$ bring the stable beliefs dangerously out of line with the fundamental value (when $n_{t}$ is particularly low).

Treatments 0 through 6 limit error to a failure to correctly price $\epsilon_{t+1}$. Treatment 7 is unique for introducing a substantial long-lived lag correlation in the pricing error. This is attributable to the failure to properly price $d_{t}$. There is persistence in the beliefs that produce the mispricing but since $\epsilon_{t+1} \sim i i d$, this persistence generates autocorrelation in the absolute pricing error but not in the error itself. With $d_{t}$ following an $\mathrm{AR}(1)$ process, persistent erroneous beliefs about how to price $d_{t}$ generates persistence in the direction of the mis-pricing as well as in its magnitude. 


\section{Discussion}

The developed market model contains a tension between a strategy of relying on imperfect fundamental information and that of seeking to optimally exploit the information content of market phenomena. Price inefficiency is inherent to a market in which traders are aware of the imperfection of their private information. Uncertainty in private information precludes the existence of the rational expectations equilibrium, forcing traders to employ behavioral accommodations. The model captures the ability of market-based information to harness the information filtering features of markets to exploit market inefficiency. The market requires both fundamental and market-based information in order to approach efficiency.

The market's invitation for traders to employ market-based information is knife-edged. The ability to contribute towards a more efficient market depends on the market-based traders holding beliefs consistent with the current state of the market. This cannot be assured because the state is typically changing as a consequence of the market-based traders trading success. Perpetually efficient operation of the market requires no sudden market changes and perpetual improvement in the market based model. Absent these features, the market-based traders introduce occasional pricing breakdown so that the price no longer reflects underlying fundamentals. Finite memory invites sudden changes.

Market-based trader errors in extracting private information can result in inefficiencies resembling noise, while errors in information processing that mis-price the present add persistent bias to price deviations. These features contribute to generate data displaying features broadly associated with actual market data. Persistence in returns is present only when the market is inefficient and remains short lived because the source of the error is also short lived. Persistence in the absolute price impact originates from the imperfect beliefs of market-based traders. The persistence is only present when the market is at its threshold in tolerating the market-based traders. The directed price impact of trader error associated with future speculation is short lived while a failure to properly price what is known in the present has lasting effect.

Empirical validation offers an avenue for further study. LeBaron (2012), He and Li (2015), and Schmitt and Westerhoff (2017a) each calibrate an agent-based model to replicate important features of market generated data. Schmitt and Westerhoff in particular model persistent price deviations from the Shiller (2015) measure of ex post prefect foresight fundamental value. Iden- 
tifying the noisy price deviations of the present model requires a measure of value responsive to the ex ante news that drives regular trading activities 


\section{References}

Branch, William A., George W. Evans. 2006. "Intrinsic Heterogeneity in Expectation Formation," Journal of Economic Theory, 127, 264-295.

Branch, William A., Bruce McGough. 2008. "Replicator Dynamics in a Cobweb Model with Rationally Heterogeneous Expectations," Journal of Economic Behavior \& Organization, 65, $224-244$.

Brock, William A., Cars H. Hommes. 1998. "Heterogeneous Beliefs and Routes to Chaos in a Simple Asset Pricing Model," Journal of Economic Dynamics and Control, 22, 1235-1274.

Brock, William A., Blake D. LeBaron. 1996. "A Dynamic Structural Model for Stock Return Volatility and Trading Volume," The Review of Economics and Statistics, 78, 94-110.

Bullard, James. 1994. "Learning Equilibria," Journal of Economic Theory, 64, 468 - 485. doi: 10.1006/jeth.1994.1077.

Bullard, James, John Duffy. 1999. "Using Genetic Algorithms to Model the Evolution of Heterogeneous Beliefs," Computational Economics, 13, 41-60. doi: 10.1023/A:1008610307810.

Bullard, James, John Duffy. 2001. "Learning and Excess Volatility," Macroeconomic Dynamics, 5, 272-302.

Chiarella, Carl, Roberto Dieci, and Laura Gardini. 2006. "Asset Price and Wealth Dynamics in a Financial Market With Heterogeneous Agents," Journal of Economic Dynamics and Control, 30, 1755-1786.

Chiarella, Carl, Xue-Zhong He. 2001. "Asset Price and Wealth Dynamics Under Heterogeneous Expectations," Quantitative Finance, 1, 509-526. doi: 10.1088/1469-7688/1/5/303.

Chiarella, Carl, Xue-Zhong He. 2003. "Dynamics of Beliefs and Learning Under AL-processesthe Heterogeneous Case," Journal of Economic Dynamics and Control, 27, 503-531.

Day, Richard H., Weihong Huang. 1990. "Bulls, Bears and Market Sheep," Journal of Economic Behavior \& Organization, 14, 299 - 329. doi: 10.1016/0167-2681(90)90061-H. 
De Grauwe, Paul, Marianna Grimaldi. 2005. "Heterogeneity of Agents, Transactions Costs and the Exchange Rate," Journal of Economic Dynamics and Control, 29, 691 - 719. doi: 10.1016/j.jedc.2004.01.004.

De Long, J. Bradford, Andrei Shleifer, Lawrence H. Summers, and Robert J. Waldmann. 1990a. "Noise Trader Risk in Financial Markets," Journal of Political Economy, 98, 703-738.

De Long, J. Bradford, Andrei Shleifer, Lawrence H. Summers, and Robert J. Waldmann. 1990b. "Positive Feedback Investment Strategies and Destabilizing Rational Speculation," The Journal of Finance, 45, 379-395.

Evans, George W., Seppo Honkapohja. 2001. Learning and Expectations in Macroeconomics.: Princeton University Press.

Evans, George W., Garey Ramey. 1992. "Expectation Calculation and Macroeconomic Dynamics," The American Economic Review, 82, 207-224.

Fama, Eugene F. 1970. "Efficient Capital Markets: A Review of Theory and Empirical Work," The Journal of Finance, 25, 383-417.

Farmer, J.Doyne, Shareen Joshi. 2002. "The Price Dynamics of Common Trading Strategies," Journal of Economic Behavior \& Organization, 49, 149-171.

Franke, Reiner, Frank Westerhoff. 2012. "Structural Stochastic Volatility in Asset Pricing Dynamics: Estimation and Model Contest," Journal of Economic Dynamics and Control, 36, 1193 - 1211. doi: http://doi.org/10.1016/j.jedc.2011.10.004.

Frankel, Jeffrey A., Kenneth A. Froot. 1990. "Chartists, Fundamentalists, and Trading in the Foreign Exchange Market," The American Economic Review, 80, 181-185.

Giardina, Irene, Jean-Philippe Bouchaud. 2003. "Bubbles, Crashes and Intermittency in Agent Based Market Models," The European Physical Journal B-Condensed Matter and Complex Systems, 31, 421-437.

Goldbaum, David. 2003. "Profitable Technical Trading Rules as a Source of Price Instability," Quantitative Finance, 3, 220-229. doi: 10.1088/1469-7688/3/3/308. 
Goldbaum, David. 2005. "Market Efficiency and Learning in an Endogenously Unstable Environment," Journal of Economic Dynamics and Control, 29, 953-978. doi: 10.1016/j.jedc.2004.08.001.

Goldbaum, David. 2006. "Self-Organization and the Persistence of Noise in Financial Markets," Journal of Economic Dynamics and Control, 30, 1837-1855. doi: 10.1016/j.jedc.2005.08.015.

Goldbaum, David, Valentyn Panchenko. 2010. "Learning and Adaptation's Impact on Market Efficiency," Journal of Economic Behavior \& Organization, 76, 635-653. doi: 10.1016/j.jebo.2010.09.003.

Grossman, Stanford J., Joseph E. Stiglitz. 1980. "On the Impossibility of Informationally Efficient Markets," The American Economic Review, 70, 393-408.

Guse, Eran A. 2010. "Heterogeneous Expectations, Adaptive Learning, and Evolutionary Dynamics," Journal of Economic Behavior \& Organization, 74, 42-57.

He, Xue-Zhong, Youwei Li. 2015. "Testing of a Market Fraction Model and PowerLaw Behaviour in the $\{\mathrm{DAX}\}$ 30," Journal of Empirical Finance, 31, 1 - 17. doi: 10.1016/j.jempfin.2015.01.001.

Hellwig, Martin F. 1980. "On the Aggregation of Information in Competitive Markets," Journal of Economic Theory, 22, 477-498.

LeBaron, Blake. 2012. "Heterogeneous Gain Learning and the Dynamics of Asset Prices," Journal of Economic Behavior \& Organization, 83, 424 - 445. doi: 10.1016/j.jebo.2012.03.003.

LeBaron, Blake, W.Brian Arthur, and Richard Palmer. 1999. "Time Series Properties of an Artificial Stock Market,” Journal of Economic Dynamics and Control, 23, 1487-1516.

Lux, Thomas. 1995. "Herd Behaviour, Bubbles and Crashes," The Economic Journal, 105, 881-896.

Lux, Thomas. 1998. "The Socio-Economic Dynamics of Speculative Markets: Interacting Agents, Chaos, and the Fat Tails of Return Distributions," Journal of Economic Behavior \& Organization, 33, 143-165. 
Marcet, Albert, Thomas J. Sargent. 1989a. "Convergence of Least-Squares Learning in Environments With Hidden State Variables and Private Information," The Journal of Political Economy, 97, 1306-1322.

Marcet, Albert, Thomas J. Sargent. 1989b. "Convergence of Least Squares Learning Mechanisms in Self-Referential Linear Stochastic Models," Journal of Economic Theory, 48, 337-368.

Panchenko, Valentyn, Sergiy Gerasymchuk, and Oleg V Pavlov. 2013. "Asset Price Dynamics With Heterogeneous Beliefs and Local Network Interactions," Journal of Economic Dynamics and Control, 37, 2623-2642.

Parke, William R., George A. Waters. 2007. "An Evolutionary Game Theory Explanation of Arch Effects," Journal of Economic Dynamics and Control, 31, 2234-2262.

Routledge, Bryan R. 1999. "Adaptive Learning in Financial Markets," Review of Financial Studies, 12, 1165-1202.

Schmitt, Noemi, Frank Westerhoff. 2017a. "Herding Behaviour and Volatility Clustering in Financial Markets," Quantitative Finance, in press. doi: 10.1080/14697688.2016.1267391.

Schmitt, Noemi, Frank Westerhoff. 2017b. "On the bimodality of the distribution of the S\&P 500's distortion:empirical evidence and theoretical explanations*," Journal of Economic Dynamics and Control. doi: 10.1016/j.jedc.2017.05.002.

Sciubba, Emanuela. 2005. "Asymmetric Information and Survival in Financial Markets," Economic Theory, 25, 353-379.

Sethi, Rajiv, Reiner Franke. 1995. "Behavioural Heterogeneity Under Evolutionary Pressure: Macroeconomic Implications of Costly Optimisation," The Economic Journal, 105, 583-600.

Shiller, Robert J. 2015. Irrational Exuberance. Princeton NJ: Princeton University Press, 3rd edition.

\section{A Appendix: Proof of Proposition 3}

Proof. Under the regularity conditions (see Marcet and Sargent (1989b), p342-343), the stability of the learning process with $\lambda_{t}=1 / t$ can be established from the stability of $T(c)-c$ where 
$T(c)$ maps $c$ into the projection coefficients. From (19) and (20),

$$
c_{1}=\frac{R}{B_{2}}
$$

and

$$
c_{2}=\frac{\phi}{R-\phi}\left(R-c_{1}\right)
$$

so that, according to (13),

$$
T\left(c_{1}\right)=\frac{n R+(1-n)\left(R-c_{1}\right) \kappa}{n \beta}
$$

and

$$
T\left(c_{2}\right)=-\frac{\phi}{R-\phi}\left(\frac{n R(1-\beta)+(1-n)\left(R-c_{1}\right) \kappa}{n \beta}\right)
$$

The eigenvalues of the Jacobian matrix, $\frac{\partial[T(\mathbf{c})-\mathbf{c}]}{\partial \mathbf{c}}$, are $\left\{-1,-1-\frac{1-n}{n} \frac{1}{\beta} \kappa\right\}$, which are both less than zero. The learning process is thus locally stable so that $\operatorname{Pr}\left(\left|\mathbf{c}_{t}-\mathbf{c}^{*}\right|>\psi\right) \stackrel{a}{\rightarrow} 0$ for $\psi>0$.

\section{B Derivation of Returns}

A meaningful return series requires that dividends and prices be left un-normalized. Let

$$
\begin{aligned}
d_{t} & =d_{0}+\eta_{t}, \\
\eta_{t} & =\phi \eta_{t-1}+\epsilon_{t},
\end{aligned}
$$

with $\epsilon_{t} \sim \operatorname{IIDN}\left(0, \sigma_{\epsilon}^{2}\right)$. Thus,

$$
p_{t}=\frac{d_{0}}{R-1}+\frac{1}{R-\phi}\left(B_{1}\left(n_{t}, c_{t}\right) \phi \eta_{t}+B_{2}\left(n_{t}, c_{t}\right) \epsilon_{t+1}\right),
$$

with $B_{1}\left(n_{t}, \mathbf{c}_{t}\right)$ and $B_{2}\left(n_{t}, \mathbf{c}_{t}\right)$ unchanged from the demeaned version. Using the HSBR condition $c_{2 t}=c_{2}^{*}\left(c_{1 t}\right)$ so that $B_{1}=1$, the return numerator solves to

$$
p_{t+1}+d_{t+1}-p_{t}=d_{0}+\frac{1}{R-\phi}\left(\phi(R-1) \eta_{t}+\left(R-B_{2 t}\right) \epsilon_{t+1}+B_{2 t+1} \epsilon_{t+2}\right) .
$$


from which the three equations of returns are readily obtained. The first two require imposing $B_{2 t}=B_{2 t+1}=0$ and $B_{2 t}=B_{2 t+1}=1$ respectively. 